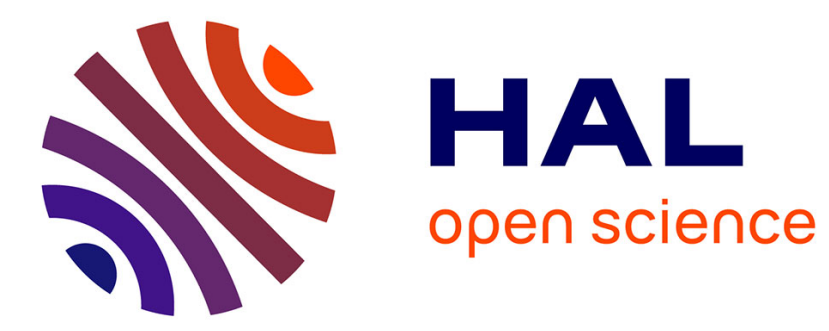

\title{
Seed coat development and dormancy
}

Isabelle Debeaujon, Loic Lepiniec, Lucille Pourcel, Jean-Marc Routaboul

\section{To cite this version:}

Isabelle Debeaujon, Loic Lepiniec, Lucille Pourcel, Jean-Marc Routaboul. Seed coat development and dormancy. Seed development, dormancy and germination, 27, Wiley-Blackwell, 392 p., 2007, Annual Plant Reviews, 10.1093/aob/mcn167 . hal-01203973

\section{HAL Id: hal-01203973 \\ https://hal.science/hal-01203973}

Submitted on 6 Jun 2020

HAL is a multi-disciplinary open access archive for the deposit and dissemination of scientific research documents, whether they are published or not. The documents may come from teaching and research institutions in France or abroad, or from public or private research centers.
L'archive ouverte pluridisciplinaire HAL, est destinée au dépôt et à la diffusion de documents scientifiques de niveau recherche, publiés ou non, émanant des établissements d'enseignement et de recherche français ou étrangers, des laboratoires publics ou privés. 
Chapter 3 (Seed Development, Dormancy and Germination ; Ed by K. Bradford \& H. Nonogaki ; Blackwell 2006, in press)

\section{SEED COAT DEVELOPMENT AND DORMANCY}

Isabelle Debeaujon, Loïc Lepiniec, Lucille Pourcel, and Jean-Marc Routaboul

Laboratoire de Biologie des Semences, Unité Mixte de Recherche 204 INRA-INAPG, Institut Jean-Pierre Bourgin, route de Saint-Cyr, 78026 Versailles, France.

\section{INTRODUCTION}

Two major types of dormancy mechanisms exist: embryo dormancy where the agents inhibiting germination are inherent to the embryo, and coat-imposed dormancy where inhibition is conferred by the seed envelopes (Bewley, 1997). Generally, complex interactions between the embryo and covering structures determine whether a seed will germinate. As a consequence, many intermediate situations are encountered due to varying contributions by the embryo and envelopes to dormancy. Seed dormancy is a typical quantitative genetic character involving many genes and being substantially influenced by environmental effects (Koornneef et al., 2002; Alonso-Blanco et al., 2003). It is an adaptative trait allowing germination to occur during the most suitable period for seedling establishment and life cycle completion.

Embryo growth potential and characteristics of the seed envelopes that determine the intrinsic capacity of a seed to germinate are established during development. The purpose of this review is to analyze the role of the seed envelopes, particularly the testa (seed coat), in dormancy and germination. The developmental events leading to the formation of the testa in 
Arabidopsis are presented. Special attention is paid to the roles played by flavonoids, particularly proanthocyanidins (condensed tannins), in determining the physicochemical characteristics of the testa that influence seed dormancy, germination and longevity in various species. In particular, the recent progress made in this field using the model plant Arabidopsis, which also illustrates the power of molecular genetics combined with physiology, is emphasized to dissect the mechanisms of seed coat-imposed dormancy.

\section{DEVELOPMENT AND ANATOMY OF THE SEED COAT}

\section{The seed envelopes}

In seed plants, the ovule consists of the embryo sac surrounded by the nucellus and integument(s) (Schneitz et al., 1995). After fertilization, the ovule develops into a seed, which contains an embryo embedded in nutritive tissues such as the endosperm (angiosperms) or the megagametophyte (gymnosperms). The embryo and the nutritive tissues are surrounded by the testa. In the family Gramineae to which the cereals such as wheat (Triticum aestivum), rice (Oryza sativa) and maize (Zea mays) belong, the "seed" is a caryopsis (called a grain), i.e. a dry and indehiscent fruit containing one seed, in which the pericarp is fused with the thin testa. In angiosperm species, the nutritive tissue of mature seeds can be either the endosperm or the perisperm. Alternatively, reserves can be stored in the cotyledons (embryonic leaves), thus distinguishing among endospermic, perispermic, and non-endospermic seed types, respectively (Werker, 1997). The testa and perisperm are maternal tissues derived from the differentiation of the integument(s) and nucellus, respectively. The endosperm and embryo are of both maternal and paternal origin because they originate from double fertilization. In mature Arabidopsis thaliana and rapeseed (Brassica napus) seeds, the endosperm is reduced to one cell layer, which is tightly associated with the testa (Iwanowska et al., 1994; Debeaujon and Koornneef, 2000) (Fig. 3.1B). It corresponds to the peripheral endosperm and is sometimes called the aleurone layer, by structural analogy to the aleurone layer of cereal 
seeds (Olsen, 2004). The cells of the aleurone layer remain alive at seed maturity. In mature Arabidopsis seeds, a thin hyaline layer without pectin also surrounds the embryo (Debeaujon et al., 2000).

The testa includes the integument(s) and the chalazal tissues (Fig. 3.1A). The testa consists of several layers of specialized cell types originating from the differentiation of ovular integuments that is triggered by fertilization. They develop from the epidermis of the ovule primordium that derives ontogenetically from the meristematic L1 cell layer (Schneitz et al., 1995). The number of ovule integuments varies depending on plant species. Most monocotyledons (e.g., wheat) and dicotyledons (e.g., Arabidopsis, bean) have two integuments (bitegmic ovules). A single integument (unitegmic ovules) is mainly found in the Rosidae, Ericales, Asteridae and Solanaceae that includes tomato, petunia and tobacco (Boesewinkel and Bouman, 1995; Angenent and Colombo, 1996). The micropyle is a pore formed by the integument(s) as an entrance for the pollen tube. The chalazal region is also an important part of the testa where the connection of the vascular tissues of the maternal funiculus to the seed ends. The scar where the funiculus was connected that remains after seed detachment is called the hilum. The differentiation of testa tissues involves important cellular changes generally ending with programed cell death (PCD).

\section{The Arabidopsis testa}

The Arabidopsis testa involves two integuments, the inner integument (ii) having three cell layers and the outer integument (oi) being two-layered(Schneitz et al., 1995; Beeckman et al., 2000) (Fig. 3.1). In the first few days after fertilization (daf), integument growth proceeds through both cell division and expansion (Haughn and Chaudhury, 2005). At the heart stage of embryo development, the cellular organization of testa tissues becomes evident and distinguishable (Fig. 3.1A), although further modifications are necessary to lead to the formation of the mature testa structure (Fig. 3.1B). 
During seed development, the individual integumentary cell layers follow different fates. The innermost cell layer (ii1), also called the endothelium, specializes in proanthocyanidin (PA) biosynthesis (Devic et al., 1999; Debeaujon et al., 2003). PAs are flavonoid compounds also known as condensed tannins (Marles et al., 2003; Dixon et al., 2005). They accumulate in vacuoles of the endothelium cells as colorless compounds during the early stages of seed development (Fig. 3.2). PA biosynthesis starts very early (around 1-2 daf) in the micropylar region and the deposition progresses towards the chalaza until around 5-6 daf. Their oxidation during the course of seed desiccation (Fig. 3.2) leads to the formation of brown pigments that confer the color of mature seeds (Stafford, 1988; Debeaujon et al., 2003; Marles et al., 2003; Pourcel et al., 2005). With the exception of a few ii2 cells at the micropyle that can accumulate PAs (Fig. 3.1A), the cells of the two other ii layers do not differentiate further from their original parenchymatic stage and are crushed at seed maturity (Debeaujon et al., 2003) (Fig. 3.1B).

Cells of oi1 and oi2 layers both first produce and degrade starch granules and afterwards fulfill different developmental fates. The oi2 layer differentiates into the surface cells containing mucilage, thickened radial cell walls and central elevations known as columellae (Western et al., 2000; Windsor et al., 2000; Haughn and Chaudhury, 2005). The mucilage accumulates in the apoplastic space of oi2 cells around the columellae. Its major component is pectin, a highly hydrophilic polysaccharide that has a gel-like consistency when hydrated (Goto, 1985; Western et al., 2000). Gibberellins (GAs) present in oi2 cells induce $\square-$ amylase for starch degradation preceding mucilage formation (Kim et al., 2005). The subepidermal oil layer produces a thickened wall on the inner tangential side of the cell, forming the palisade layer (Goto, 1985; Western et al., 2000). It also accumulates flavonols, which are colorless to pale yellow flavonoids (Pourcel et al., 2005) (Fig. 3.1). 
The cell walls of endothelial cells (ii1) facing the aleurone layer are bordered by an electron-dense layer that reacts positively to osmium tetroxide, suggesting its lipidic nature (Beeckman et al., 2000) (Fig. 3.1). The same layer also appears strongly refringent in seed confocal sections (Garcia et al., 2003). This layer corresponds to the cuticle (ct) originally present in the inner integument during development (Beeckman et al., 2000). Such a cuticle was found only at the surface of cells facing the endosperm and not on the other integument layers (Fig. 3.1). Some cells in the chalazal region (pigment strand [ps]) of the Arabidopsis testa are also able to accumulate PAs, which creates a continuum of tannin-producing cells with a bulb-like shape at the chalazal pole, just above the end of the vascular bundle (vb) from the funiculus (Fig. 3.1A), corresponding to the pigment strand in cereals (Zee and O'brien, 1970; Debeaujon et al., 2003). There is also a very small amount of remaining nucellus (chalazal proliferating tissue [cpt]) at the chalazal pole of the seed (Beeckman et al., 2000) (Fig. 3.1A).

Testa growth and differentiation proceed coordinately with development of the endosperm and embryo. However, as the integuments are not directly involved in fertilization, some signal(s) produced during or following fertilization must coordinate the differentiation of the testa concomittantly with embryo and endosperm development (Haughn and Chaudhury, 2005). Garcia et al. (2003) presented genetic evidence that the Arabidopsis HAIKU protein is an endosperm-derived signal stimulating elongation (but not division) of integument cells, together with endosperm and embryo proliferation and growth. On the other hand, prevention of cell elongation in the integuments by mutations in the TRANSPARENT TESTA GLABRA2 (TTG2) gene restricts endosperm and seed growth (Garcia et al., 2005). The authors suggest that regulatory crosstalk between the integuments and endosperm is the primary regulator of the coordinated control of seed size in Arabidopsis. 
The Arabidopsis testa cells undergo PCD during seed development and maturation (Haughn and Chaudhury, 2005). The first cell layers that initiate this process are the parenchymatic ii2 and ii1' layers from the inner integument (Fig. 3.1). Nakaune et al. (2005) have found a correlation between the presence of VPE (VACUOLAR PROCESSING ENZYME), a cysteine proteinase with caspase-like activity, in these cell layers and their subsequent PCD. It is not known whether similar mechanisms promote PCD in the other cell layers. PCD involving a cysteine proteinase (BnCysP1) was also reported to occur in the inner integument of rapeseed testa, which suggests that this process is conserved at least among members of the Brassicaceae family (Wan et al., 2002).

Testa structure is used in determining taxonomic relationships among members of the Brassicaceae family (Vaughan and Whitehouse, 1971; Bouman, 1975). In contrast to Arabidopsis, the mature testa of rapeseed lacks mucilage in the outer integument and, for most varieties, exhibits a brown to black color due mainly to the presence of PAs (Marles and Gruber, 2004). It also has a strong palisade layer composed of cells with thickened radial walls (stellar cells) that are impregnated with phenolics at maturity. Seeds at the heart stage of embryo development exhibit a 4-layered outer integument and a 5-7-layered inner integument. PAs are detected in the innermost layer of the ii, which therefore may be functionally homologous to the Arabidopsis endothelium (Iwanowska et al., 1994; Naczk et al., 1998).

\section{ROLE OF THE SEED COAT IN SEED DORMANCY AND GERMINATION}

\section{Constraints imposed by the seed coat}

Germination begins with water uptake by the quiescent dry seed and is completed by radicle protrusion through the tissues surrounding the embryo. It occurs when the growth potential of the embryo can overcome the constraints imposed by the covering structures 
(Bewley and Black, 1994). An intact viable seed is considered to be dormant when it is unable to germinate under environmental conditions that are appropriate for germination (Bewley, 1997). To understand dormancy mechanisms, it is necessary to know what constraints the envelopes impose and why the embryo can not overcome them (Bewley and Black, 1994). The main effects exerted by the tissues surrounding the embryo are: 1) interference with water uptake; 2) mechanical restraint to radicle protrusion; 3) interference with gas exchange, particularly oxygen and carbon dioxide; 4) prevention of inhibitor leakage from the embryo; 5) supply of inhibitors to the embryo; and 6) light filtration (Werker, 1980/81, Kelly et al., 1992, Bewley and Black, 1994, Werker, 1997) (Fig. 3.3).

Many studies have demonstrated that phenolic compounds, particularly flavonoids (Fig. 3.4), contribute to the germination-inhibiting effects mentioned above. Several other physicochemical characteristics of the envelopes other than phenolics, such as specific structural elements and the presence of mucilage, cutin or callose, also influence coatimposed dormancy (Werker, 1980/81; Kelly et al., 1992; Werker, 1997). Here, we will illustrate examples of the contribution of phenolic compounds to seed dormancy in several plant families.

\section{Flavonoids in Arabidopsis seeds}

\section{Main flavonoid end-products present in seeds}

Arabidopsis seeds accumulate only flavonols and proanthocyanidins (Routaboul et al., 2005) (Fig.3.4). Flavonols are present mainly as glycoside derivatives, and are found in the testa (essentially the oil layer), endosperm and embryo (Pourcel et al., 2005; Routaboul et al., 2005) (Fig. 3.1). In mature seeds, the major flavonol is quercetin-3-O-rhamnoside (Q-3-O-R). Recently, a novel group of biflavonols (quercetin-rhamnoside dimers) has been detected. Both Q-3-O-R and biflavonols are found mainly in the testa (Routaboul et al., 2005). 
PAs are present specifically in the testa (Fig. 3.1). In most plant species, PAs are generally polymers of the two flavan-3-ol stereoisomers epicatechin (EC, 2-3-cis) and catechin (C, 2-3-trans) (Dixon et al., 2005). However, Arabidopsis seeds accumulate only EC polymers. The mean degree of polymerization varies between 5 and 8 , depending on the accessions (Abrahams et al., 2003; Routaboul et al., 2005). Interestingly, natural variation in the quantity of PAs also occurs among accessions (Lepiniec et al., 2006). A detailed characterization of flavonoid metabolome in seeds of Arabidopsis mutants and natural accessions using liquid chromatography-tandem mass spectrometry (LC-MS) and nuclear magnetic resonance (NMR) methods has been undertaken (Routaboul et al., 2005) with the aims of drawing correlations between germination/dormancy behaviors and specific flavonoid products and isolating novel flavonoid mutants that may not have clear color phenotypes.

Purple anthocyanins are also present in Arabidopsis, but only in vegetative parts (Shirley et al., 1995). They are conspicuous in 4-day-old seedlings and in aging plants exhibiting chlorophyll degradation.

\section{Molecular genetics of flavonoid metabolism}

\section{The mutants}

Most Arabidopsis mutants impaired in flavonoid biosynthesis have been identified through visual screenings of various collections for altered seed coat pigmentation (Koornneef, 1990; Shirley et al., 1995; Lepiniec et al., 2006). As such, they are all affected in PA metabolism. Mutant seed colors range from pale yellow to pale brown or gray, with the chalaza and micropyle remaining normally pigmented in some of them. The fls 1 (flavonol synthase 1) mutant, obtained through reverse genetics (Wisman et al., 1998), lacks only flavonols because of a mutation in the FLS1 gene (Fig. 3.4) and produces brown seeds like the 
wildtype (WT) due to the presence of oxidized PAs (Routaboul et al., 2005). No mutant seeds whose testa color is significantly darker than WT have been reported in Arabidopsis.

Twenty-three genetic complementation groups of testa mutants have been identified. Many mutants have been collectively called transparent testa ( $t t)$ mutants ( $t t 1$ to $t t 19$ ), or $t t$ glabra (ttg1 and ttg2) (Koornneef, 1990; Shirley et al., 1995; Lepiniec et al., 2006). The banyuls (ban) mutant is unique in the fact that it accumulates anthocyanins in place of PAs (Albert et al., 1997). The tt10 mutant is also exceptional because it does not affect the biosynthesis of PAs but their subsequent oxidative browning (Pourcel et al., 2005). Six independent mutations affecting PA biosynthesis (tannin-deficient seed; tds 1 to 0 ) have been reported (Abrahams et al., 2002). It is not known whether these represent additional loci except for $t d s 4$, which is allelic to $t t 18$ (Abrahams et al., 2003). In addition, the $t t 11$ and $t t 14$ mutants appear to be allelic to $t t 18$ and $t t 19$, respectively (I. Debeaujon and M. Koornneef, unpublished results). Seed pigmentation mutants may be deprived of anthocyanins in vegetative parts if the mutation affects the general core flavonoid pathway (Fig. 3.4). A classification of the 23 mutants on the basis of their flavonoid composition in seed and vegetative tissues is presented in Table 3.1.

\section{The proteins}

Twenty genes have already been characterized at the molecular level (see Lepiniec et al., 2006 for a detailed review). Nine genes encode biosynthetic enzymes (chalcone synthase [CHS], chalcone isomerase [CHI], flavanone 3-hydroxylase [F3H], flavanone 3'-hydroxylase [F3'H], dihydroflavonol reductase [DFR], leucoanthocyanidin dioxygenase [LDOX], glycosyltransferase [GT], flavonol synthase 1 [FLS1], and anthocyanidin reductase [ANR]) and one gene encodes a modification enzyme (laccase 15 [LAC15]) (Fig. 3.4). FLS1 and LAC15 are the only known flavonoid-related enzymes encoded by more than one gene in 
Arabidopsis. In addition to FLS1, five other genes (FLS2 to 6) exhibit sequence homology with flavonol synthases (Alerding et al., 2005), although it is not yet known whether they are also involved in flavonol biosynthesis. The TT10 gene has been cloned and shown to encode a polyphenol oxidase of the laccase type that belongs to a multigene family containing 17 members (Pourcel et al., 2005). TT10 (LAC15) is involved in the formation of epicatechin quinones that spontaneously polymerize into brown derivatives (Fig.3.4). It may catalyze the oxidative browning of colorless PAs, which is consistent with the fact that $t t 10$ has normal PA levels but yellow seeds at harvest. TT10/LAC15 also catalyzes the formation of biflavonols from quercetin rhamnoside, probably in the oil layer (see below the description of TT10/LAC15 promoter activity). Interestingly, TT10/LAC15 expression is lower in the Landsberg erecta (Ler) accession than in Wassilevskija (Ws-2) and Columbia (Col), consistent with a reduction in enzyme activity because Ler exhibits twice the amount of soluble PAs (corresponding to less oxidized PAs) compared to Ws-2 and Col (Pourcel et al., 2005; Routaboul et al., 2005). The biological role of TT10/LAC15 during seed development may be to strengthen the testa to protect the embryo and endosperm from biotic and abiotic stresses.

The genes encoding Desmodium uncinatum leucoanthocyanidin reductase (LAR) and Arabidopsis and Medicago truncatula ANR are involved specifically in PA biosynthesis (Tanner et al., 2003; Xie et al., 2003; Dixon et al., 2005). The corresponding recombinant proteins catalyze the formation of trans-flavan-3-ols (e.g., catechin) and cis-flavan-3-ols (e.g., epicatechin), respectively (Tanner et al., 2003; Xie et al., 2004). In Arabidopsis, ANR is encoded by the BANYULS (BAN) gene (Devic et al., 1999). However, no sequence with significant homology to LAR enzymes has been found in the Arabidopsis genome. This is consistent with the fact that only epicatechin is synthesized in this species (Abrahams et al., 2002; Routaboul et al., 2005). 
Six loci in Arabidopsis (TT1, TT2, TT8, TT16, TTG1 and TTG2) have a regulatory function in PA biosynthesis. TT2, TT8, and TTG1 encode a R2R3-MYB protein (Nesi et al., 2001), a basic helix-loop-helix (bHLH) protein (Nesi et al., 2000), and a WD40 protein (Walker et al., 1999), respectively. The corresponding mutants produce seeds with no PAs. The $t \operatorname{tg} 1$ and $t t 8$ (but not $t t 2$ ) mutants are also affected in anthocyanin biosynthesis in vegetative tissues (Koornneef, 1981; Shirley et al., 1995). This is consistent with the specific expression of TT2 in PA-producing cells (Nesi et al., 2001; Debeaujon et al., 2003), whereas TT8 and TTG1 are expressed also in vegetative parts (Walker et al., 1999; Nesi et al., 2001; Baudry et al., 2004). TT1 and TT16/ABS code a zinc-finger protein and a "B-sister" group MADS box protein, respectively (Becker et al., 2002; Nesi et al., 2002; Sagasser et al., 2002). Both are necessary for the pigmentation in the endothelium, but not in the micropyle and chalazal areas. TTG2 encodes a WRKY transcription factor and mutation of this gene leads to the formation of completely yellow seeds (Johnson et al., 2002). Epistatic relationships suggest that TTG2 acts downstream of TTG1 in regulating PA accumulation.

Three proteins are probably involved in flavonoid compartmentation (epicatechin transport into vacuoles): a MATE secondary transporter, a $\mathrm{H}^{+}$-ATPase and a glutathione-Stransferase encoded by TT12, AHA10 and TT19, respectively (Debeaujon et al., 2001; Kitamura et al., 2004; Baxter et al., 2005). Expression of the TT12 (MATE secondary transporter), BAN (ANR), TT3 (DFR) and TT18 (LDOX) genes was absent in mutants defective in TT2 (MYB), TT8 (bHLH) and TTG1 (WD40), suggesting regulatory roles for these transcription factors in the induction of PA biosynthesis and transport enzymes (Nesi et al., 2000; Nesi et al., 2001; Debeaujon et al., 2003). 
Regulation of BANYULS and TT10 gene expression

Promoter activity of both $B A N$ and $T T 10 / L A C 15$ were analyzed using a promoter:reporter approach to obtain more insights into the tissue specificity of their transcriptional regulation. $B A N$ promoter activity was detected mainly in cells accumulating PAs (Debeaujon et al., 2003; Sharma and Dixon, 2005). The TT10/LAC15 promoter exhibited a more complex pattern of regulation than that of the $B A N$ promoter, appearing first in the endothelium and then in the oil cell layer. Expression was correlated with PA- and flavonolproducing cells (Fig. 3.1), which is consistent with the role for TT10/LAC15 in flavonoid metabolism in the testa. Characterization of $B A N$ - and TT10/LAC15-promoter:reporter constructs in the the $t t 2, t t 8$, and $t \operatorname{tg} 1$ regulatory mutants demonstrated that $T T 2, T T 8$ and TTG1 are necessary for $B A N$ expression but not for TT10/LAC15 (Debeaujon et al., 2003; Pourcel et al., 2005). These promoter:reporter constructs provide valuable markers for the PAand flavonol-accumulating cells in the Arabidopsis testa.

\section{Effects of flavonoids on seed dormancy and germination}

Flavonoids, particularly condensed tannins, have been shown to reinforce coatimposed dormancy by increasing testa thickness and mechanical strength. Indeed, cell layers containing pigments generally do not crush as dramatically as the non-pigmented ones (Debeaujon et al., 2000). Moreover, during oxidation PAs have a tendency to cross-link with proteins and carbohydrates in cell walls, thus reinforcing testa structure and also modifying its permeability properties (Marles et al., 2003; Marles and Gruber, 2004). This was demonstrated using Arabidopsis mutants affected in flavonoid metabolism in the testa (LéonKloosterziel et al., 1994; Focks et al., 1999; Debeaujon and Koornneef, 2000; Debeaujon et al., 2000; Debeaujon et al., 2001). Freshly harvested mutant seeds lacking PAs germinate faster than the corresponding WT brown seeds (Fig. 3.5A). Moreover, their mature testa is 
thinner and more permeable to tetrazolium salts (Debeaujon et al., 2000). Permeability to water, an important parameter for germination, could not be examined with $t t$ mutants by the traditional seed water content analysis that depends on weighing seeds during imbibition because of the presence of a hydrophylic mucilage excreted by the outer integument. NMR imaging may represent an alternative method to analyze water distribution inside seeds, as demonstrated in tobacco (Nicotiana tabaccum) and white pine (Pinus monticola) (Manz et al., 2005; Terskikh et al., 2005).

Reduced seed dormancy observed in $t$ mutant seeds is controlled maternally based on germination of F1 seeds resulting from reciprocal crosses between $t$ mutants and WT (Fig. 3.5B). This is consistent with the fact that the testa derives from the integuments, which are maternal tissues. Little difference in germination between $t t$ mutant and WT seeds is observed when they are after-ripened, suggesting that the "seed coat" effect is particularly conspicuous under physiological conditions unfavorable for germination such as embryo dormancy (Debeaujon et al., 2000). Seeds of the Arabidopsis gal mutant are deficient in GAs and thus unable to germinate in the absence of additional GAs. The $t t 4$ mutant (CHS deficient; Fig. 3.4) is deprived of flavonoids and exhibits reduced testa inhibition of germination. Genetically reducing the testa inhibition in gal seeds (in a gal tt4 double mutant) enabled germination of non-dormant seeds without GA requirement (Fig. 3.5C). This experiment also showed that both cold and light may in part be able to stimulate germination independently from GAs (Debeaujon and Koornneef, 2000).

The permeability of the Arabidopsis testa to exogenous GAs and GA biosynthesis inhibitors (tetcyclacis [TET] and paclobutrazol [PAC]) was also increased in $t t$ mutants. (Debeaujon and Koornneef, 2000; Fig. 3.5D). Application of $100 \square \mathrm{M}$ PAC reduces germination of both $t t 2-3$ and WT seeds, which is gradually rescued by increasing concentrations of exogenous GAs. Relatively lower concentrations $(>0.01 \square \mathrm{M})$ of GAs enables $t t 2-3$ seeds to germinate in the 
presence of PAC, while much higher concentrations $(>10 \square \mathrm{M})$ of GAs are required to recover PAC-inhibited WT seed germination (Fig. 3.5D). The higher response (permeability) of seeds to GAs compared to WT was also observed in pigment-less seeds produced by the pBAN::BARNASE translational fusion line (Debeaujon et al., 2003). In this line, cytotoxic gene $B A R N A S E$ was expressed using $B A N$ gene promoter which drove specific expression in PA-producing cells, leading to their genetic ablation and as a consequence, to the formation of pigment-less seeds. These seeds were capable of germinating in relatively lower concentrations of GAs in the presence of PAC, in the same way than typical $t t$ seeds (Fig. 3.5D). Therefore flavonoids and no other physicochemical factor present in PA-producing cells are significantly responsible for the $t t$ germination phenotype.

Abscisic acid (ABA) is synthesized de novo in primary dormant Arabidopsis seeds during imbibition (Debeaujon and Koornneef, 2000; Ali-Rachedi et al., 2004). Freshly harvested gal $\mathrm{tt} 4$ seeds were able to germinate to $50 \%$ in the presence of carotenoid synthesis inhibitor norflurazon, which inhibits ABA biosynthesis, while gal seeds exhibited only 5\% germination (Debeaujon and Koornneef, 2000).

Together, these data suggest that GAs are necessary during Arabidopsis germination essentially to overcome the restraints to radicle protrusion imposed by the testa and de novosynthesized ABA. Removal of seed envelopes (testa and endosperm) allows germination of both gal seeds and freshly harvested Cape Verde Islands (Cvi) seeds, which have a strong primary dormancy (Debeaujon and Koornneef, 2000; Alonso-Blanco et al., 2003). It is possible that coat removal enables ABA leakage from dormant seeds, thus releasing dormancy, but this still remains to be investigated. Analysis of natural allelic variation between the Cvi and Ler accessions revealed a quantitative trait locus (QTL) with a maternal effect (Delay of Germination2 [DOG2]). The authors hypothesized that DOG2 may affect seed coat-imposed dormancy through the genetic structure of the testa, or a factor imported 
from the mother plant (Alonso-Blanco et al., 2003) (see Chapter 6). The $t t$ mutants exhibit normal ABA sensitivity, although some of them showed a slight decrease in sensitivity (Debeaujon and Koornneef, unpublished results). This may indicate that flavonoids do not affect permeability of the testa to ABA as much as they affect GA permeability. PAs have been shown to act as GA antagonists in pea (Pisum sativum) (Corcoran et al., 1972; Green and Corcoran, 1975). Similarly, (+)-catechin extracted from bean (Phaseolus vulgaris) seeds was shown to act as an inhibitor of GA biosynthesis, blocking the conversion of $\mathrm{GA}_{12}$ aldehyde to $\mathrm{GA}_{12}$; the catechin was localized mainly in the testa and not in the embryo during seed maturation (Kwak et al., 1988). Moreover, Buta and Lusby (1986) observed that catechin and epicatechin inhibited Lespedeza seed germination and seedling growth. These data suggest that PAs and their precursors may inhibit germination not only by influencing the structural properties of the testa at maturity, but also by acting as biochemical inhibitors of GA metabolism and action when released from the testa during seed imbibition. Whether this biological effect is specific to GA metabolism or common to other biosynthetic pathways remains to be investigated more thoroughly.

Testa permeability is an important parameter to consider when undertaking germination experiments to test the effect of any exogenous substances on embryo behavior. For example, Rajjou et al. (2004) used $t t 2$ mutant seeds totally lacking PAs in the testa to test the effect of the transcription inhibitor $\square$-amanitin on seed germination. In preliminary experiments the authors had established that $t t 2$ seeds were far more permeable to the molecule than WT seeds. Therefore, they were able to conclude that the inability of $\square$ amanitin to block radicle protrusion was not likely due to inability of this substance to cross the testa and reach the embryo.

The $t t 12$ mutant came out of a reduced dormancy screen and was isolated on the basis of a faster seed germination of freshly harvested seeds on water (Debeaujon et al., 2001). 
Recently, several $t t$ mutants were isolated from a screen for fast seed germination at $10^{\circ} \mathrm{C}$ (Salaita et al., 2005). These additional examples confirm that testa flavonoid defects enable the seed to germinate quicker in unfavorable conditions.

Desiccation plays an important role in switching seeds from a developmental mode to germinative mode. Premature drying can redirect metabolism from a developmental to a germination program (Kermode, 1995). In $t t$ mutant seeds that have more permeable testae, the embryo might dehydrate quicker than WT embryos and therefore shift earlier from the developmental to germinative mode. The earlier loss of dormancy and shift to the germinative mode could cause precocious germination, as was observed in drying siliques of the $t t 16$ mutant (Nesi et al., 2002).

\section{Flavonoids in seed dormancy and germination of various species}

\section{Solanaceae}

Mutants affected in flavonoid metabolism were also isolated in tomato (Lycopersicon esculentum). The mutants anthocyaninless of Hoffmann (ah), anthocyanin without (aw) and baby lea syndrome (bls) contain drastically reduced or no PAs in the endothelium. Absence of PAs in the testa probably enhances its permeability to water, since the mutant seeds exhibit increased seed weight (or water content) during imbibition (Atanassova et al., 2004). Moreover, seeds of the three mutants germinate faster than the corresponding WT lines not only in optimal but also in stress conditions such as high and low temperatures $\left(33^{\circ} \mathrm{C}\right.$ and $13^{\circ} \mathrm{C}$, respectively), high salinity $(120 \mathrm{mM} \mathrm{NaCl})$ and high osmoticum (15\% polyethyleneglycol). Mutations $a h$ and $b l s$ both resulted in coordinated reduction in CHS, F3H and DFR activities (Fig. 3.4), while $a w$ completely lacked DFR activity (Atanassova et al., 1997a, 1997b). On the other hand, brownseed (bs1 to bs4) and blackseed (bks1) mutants are tomato mutants with darker testae than WT that display poor germination rates and 
percentages (Downie et al., 2004). They accumulate an additonal dark pigment in the cell layers surrounding the endothelium, which itself contains normal levels of PAs. In $b k s l$ seeds, the black pigment is a melanic substance that also enhances the mechanical strength of the testa. The phenotypes of the $b s$ and $b k s$ mutations are determined by the embryo and the endosperm, in contrast to the $a h, a w$, and $b l s$ mutants that exhibit the typical maternal control. These results suggest that the endosperm and embryo may secrete a factor that influences testa characteristics (Downie et al., 2003). Seeds of the $b s 1$ and $b s 4$ mutants have increased catalase activity, and $b s 4$ seeds also exhibit increased peroxidase activity (Downie et al., 2004). Likewise, maize grains that overexpress a gene encoding a laccase-type fungal polyphenol oxidase become brown and exhibit poor germination (Hood et al., 2003).

\section{Water permeability of testae in Leguminosae and other species}

The fact that flavonoids increase coat-imposed dormancy by restricting the permeability of the testa to water is best exemplified by so-called "hard seed", which have been abundantly described in the Leguminosae family (Wyatt, 1977; Legesse and Powell, 1992; Serrato-Valenti et al., 1994; Kantar et al., 1996; Legesse and Powell, 1996). In the genus Pisum, seeds with impermeable testae, such as the wild pea (P. elatius), have high phenolic contents and catechol oxidase activity, while species having seeds with permeable testae, such as the cultivated pea ( $P$. sativum), do not. It is hypothesized that during seed desiccation, oxidation of phenolic compounds into the corresponding quinones by catechol oxidase in the presence of molecular oxygen may trigger testa impermeability. Permeability is inversely proportional to the phenolics content and their degree of oxidation, probably through some tanning reaction (Marbach and Mayer, 1974; Stafford, 1974; Marbach and Mayer, 1975; Werker et al., 1979). Gillikin and Graham (1991) proposed that an anionic peroxidase may play a role in the hardening of soybean (Glycine max) seed coats. In this species, the majority of peroxidase activity detected in seeds is localized in the testa. In cotton 
(Gossypium hirsutum) seed also, oxidation of seed coat tannins during ripening causes seed coloration and reduction of testa permeability to water (Halloin, 1982).

\section{Flavonoids and other phenolics as direct and indirect germination inhibitors}

Flavonoids (PAs, catechin, epicatechin), phenolic acids (caffeic, p-coumaric, ferulic, sinapic, vanillic acids) and lignans have been considered as possible germination inhibitors. Seed germination is reduced in the presence of exogenous phenolics in a dose-dependent manner (Buta and Lusby, 1986; Reigosa et al., 1999; Gatford et al., 2002; Basile et al., 2003; Cutillo et al., 2003). The presence of phenolic compounds in developing grains is correlated with the prevention of pre-harvest sprouting (PHS, i.e. germination on the ear in high relative humidity) in cereals (Weidner et al., 2002). Wrobel et al. (2005) have shown that the amount of tannins and phenolic acids present in mature dry seeds of riverbank grape (Vitis riparia) was reduced during cold stratification (imbibition in cold conditions), possibly by leaching into the surrounding medium. Zobel et al. (1989) followed the changes in phenolic localization in rapeseed seeds during imbibition and found that after $3 \mathrm{~h}$ of imbibition, part of the phenolic compounds originally found in the testa leached onto the embryo surface, where they could potentially exert an inhibitory effect on radicle protrusion.

Tissues surrounding the embryo might interfere with seed germination by impeding oxygen entry or escape of carbon dioxide, which could inhibit respiration (Bewley and Black, 1994). Flavonoids are efficient antioxidants (Rice-Evans et al., 1997). When present in seed coats, they may fix molecular oxygen through reactions catalyzed by polyphenol oxidases and peroxidases and also through autoxidation, therefore limiting oxygen availability for the embryo. Similarly, the dormancy-imposing glumellae of barley (Hordeum vulgare) grains also consume oxygen (Lenoir et al., 1986). Restricted oxygen diffusion through the seed coat and an increased sensitivity of the embryo to hypoxia cause a coat-imposed dormancy of muskmelon (Cucumis melo) seeds at low temperature (Edelstein et al., 1995). Porter and 
Wareing (1974) suggested that the presence of germination inhibitors in Xanthium pennsylvanicum seeds results in a high oxygen requirement because the removal of inhibitors occurs by oxidation. This is supported by experiments using beechnut (Fagus sylvatica) seeds, where covering structures prevent germination by interfering not only with water uptake but also with oxygen availability. In this case, oxygen was demonstrated to be involved in oxidative degradation of ABA using $(+)-\left[{ }^{3} \mathrm{H}\right] \mathrm{ABA}$ (Barthe et al., 2000). The testa may impose an indirect restraint to radicle protrusion by impeding $\mathrm{ABA}$ leakage from the embryo in yellow cedar (Chamaecyparis nootkatensis) seeds (Ren and Kermode (1999).

Flavonoid pigments in the testa are likely to act as filters modifying the spectrum of light received by the embryo. Flavonols present in the testa efficiently absorb ultraviolet (UV) light, protecting the embryo from radiation damage (Winkel-Shirley, 2002a; Griffen et al., 2004). However, no data are available for absorption of other light wavelengths, particularly red light known to induce GA biosynthesis through phytochrome action (Yamaguchi et al., 1998).

\section{Pre-harvest sprouting in cereals}

Important crop species such as wheat, barley, rice and sorghum (Sorghum bicolor) exhibit low dormancy during grain development, leading to a susceptibility to PHS. Wheat grain dormancy is controlled both by maternally-expressed $R$ (Red grain color) genes conferring red pericarp pigmentation and by other genes such as $P h s$ that has a major effect in the embryo. Therefore, wheat PHS is regulated both by coat-imposed and embryonic pathways controlled by separate genetic systems (Flintham, 2000; Himi et al., 2002; Mares et al., 2002). Dominant alleles of $R$ promote the biosynthesis of red phlobaphenes (Fig. 3.4). Recently, the wheat $R$ gene was cloned and shown to encode a MYB-type transcription factor (Himi and Noda, 2005). This protein is involved in activation of the early biosynthetic genes 
CHS, CHI, F3H and DFR (see Fig. 3.4 for the pathway), which is consistent with its role in phlobaphene biosynthesis (Himi et al., 2005). Genetic resolution from the QTL approach is insufficient to determine whether the $R$ gene increases dormancy by itself or is linked to another dormancy-promoting locus. Analyzing dormancy of white-grained wheats overexpressing $R$ in the pericarp could help answer this question. In weedy rice, which is far more dormant than cultivated rice, red or black pericarp and red or black hull (palea and lemma) were correlated with deep seed dormancy. QTL have been found for these characters (Gu et al., 2005). Synteny among cereal species enables comparison of wheat PHS loci to maize and rice seed dormancy loci, allowing application of the available rice genomic DNA sequence to PHS research in other cereals (Gale et al., 2002).

\section{Heteromorphism and physiological heterogeneity among seeds}

Heteromorphism (heteroblasty) is caused by maternal factors within an individual plant, such as the position of the seed in the fruit or in the inflorescence, that influence the color, shape or size and therefore germination capacity of seeds. The resulting physiological heterogeneity provides a very important ecological advantage, especially under extreme climates (Gutterman, 2000; Matilla et al., 2005). Individual siliques of Brassica rapa contain seeds that differ in seed color: black, dark brown and light brown. Light-brown seeds are more water-permeable than black seeds, which is correlated to a faster germination. They are also more responsive to exogenous ethylene than black or dark-brown seeds (Puga-Hermida et al., 2003).

Heterogeneity in seed dormancy can also be generated by the light environment. Dormancy of mature Chenopodium album seeds are influenced by the photoperiod that the mother plant experiences during seed development. Seeds obtained from plants grown under long days (LD, $18 \mathrm{~h}$ light per day) produce small dormant seeds with thick and black testae, 
whereas plants grown under short days (SD, $8 \mathrm{~h}$ light per day) produce large non-dormant seeds with thinner brownish testae. It is generally known that photoperiodic plants monitor the length of the dark period. Consequently, a short $(1 \mathrm{~h})$ exposure of red light to interrupt the long night under short day conditions (termed SDR by the author), mimicked long-day conditions and made the maternal plants produce dormant seeds (Karssen, 2002). However, these seeds did not have black testae. Dormancy of SDR seeds was released by 3-months of after-ripening, while the authentic black testa dormant seeds produced under LD were still dormant after 3 months. Together, these data suggested that two types of dormancy are present in this species: embryo dormancy and seed coat-imposed dormancy, and that total light energy received by the plant is important for determining the second type (Karssen, 2002).

\section{Interactions with endosperm}

The impact of the endosperm on Arabidopsis seed germination is still a matter of debate. Interactions between the testa and endosperm may influence germination behavior. It is possible that enzymes secreted by endosperm cells may hydrolyze some components of testa cell walls and thus reduce their resistance (Dubreucq et al., 2000 ; Leubner-Metzger, 2002). In turn, hydrolase inhibitors may leach from the testa during imbibition. Another hypothesis would be that hydrolytic enzymes weaken the endosperm itself on the model of the tomato endosperm, which was proposed to be a more important obstacle to radicle protrusion than the testa (Groot et al., 1988; Chen et al., 2002). No mutant affected specifically in the structure of the endosperm has been recovered until now that could shed some light on its contribution to Arabidopsis seed germination. 


\section{LINK BETWEEN SEED COAT-IMPOSED DORMANCY AND LONGEVITY}

When seeds deteriorate, they lose vigor, become more sensitive to stresses during germination and finally become unable to germinate. The rate of aging is strongly influenced by storage temperature, seed moisture content and seed quality (Walters, 1998). The seed coat performs important functions to protect the embryo and seed reserves (Mohamed-Yasseen et al., 1994; Boesewinkel and Bouman, 1995) and as such, seed coat-imposed dormancy and longevity are directly related. Indeed, the physicochemical characteristics of the seed coat that determine the level of coat-imposed dormancy are also instrumental in protecting the seeds from stressful environmental conditions during storage and upon germination. For instance, lignin content in the soybean testa correlates with seed resistance to mechanical damage (Capeleti et al., 2005). Flavonols present in the testa of B. rapa protect the embryo from UVB radiation (Griffen et al., 2004). PAs were shown to deter, poison or starve bruchid larvae feeding on cowpea (Vigna unguiculata) seeds (Lattanzio et al., 2005). Defense-related proteins such as chitinases, polyphenol oxidases and peroxidases are prevalent in testa of Arabidopsis and soybean (Glycine max) (Gillikin and Graham, 1991; Gijzen et al., 2001; Pourcel et al., 2005). Flavonoids present in the testa, particulary PAs, provide a chemical barrier against infections by fungi due to their antimicrobial properties (Scalbert, 1991; Skadhauge et al., 1997; Islam et al., 2003; Aveling and Powell, 2005). They also limit imbibitional damage due to solute leakage by decreasing testa permeability thus controlling the rate of water uptake (Kantar et al., 1996). Oxidative degradation of proteins was shown to occur during development, germination and aging of Arabidopsis seeds (Job et al., 2005). It is possible that flavonoids have a beneficial effect on seed longevity by scavenging free radicals. Yellow-seeded flax (Linum usitatissimum) showed higher tendency of germination loss compared to dark seeds after accelerated aging (Diederichsen and Jones-Flory, 2005). Germination of Arabidopsis mutant seeds exhibiting testa defects, such as tts and aberrant 
testa shape (ats), was reduced more compared to WT after both long-term ambient storage and controlled deterioration, confirming the importance of seed coat integrity for seed longevity (Debeaujon et al., 2000; Clerkx et al., 2004).

\section{CONCLUDING REMARKS}

The contribution of seed envelopes, particularly the testa, to the level of seed dormancy and germination is important and needs to be appreciated to have a complete and integrative understanding of the seed dormancy. This requires anatomical, histochemical and chemical analysis of the developing testa until maturation to identify the factors playing roles in dormancy. Moreover, the physiological response of the seed to the environmental conditions prevailing at imbibition must be dissected. A better understanding of the genetic and molecular events during testa development and differentiation not only improves our fundamental knowledge on the important contribution of this multifunctional organ in seed biology, but also may open the way toward: (1) the discovery of molecular markers linked to precise testa quality parameters, which can be used in plant breeding; and (2) the genetic engineering of these testa characters to fulfill requirements for seed quality, which includes characters influencing not only seed dormancy and germination but also longevity. Fundamental knowledge obtained on flavonoid metabolism in Arabidopsis testa will speed up the improvement of seed quality in crop plants, such as rapeseed. 
Table 3.1 Classification of testa mutants based on their flavonoid composition.

Proanthocyanidins (PAs) and flavonols present in seeds were assessed either by histochemistry (vanillin or dimethylamino cinnamaldehyde [DMACA] staining for PAs, and diphenylboric acid-2-aminoethyl ester [DPBA] for flavonols) or liquid chromatographytandem mass spectrometry (LC-MS). Presence or absence / reduction are noted + and -, respectively. Anthocyanins were detected by visually examining their purple color. Data from various published and unpublished works are summarized (Shirley et al., 1995; Albert et al., 1997; Wisman et al., 1998; Focks et al., 1999; Debeaujon et al., 2001; Abrahams et al., 2002; Johnson et al., 2002; Nesi et al., 2002; Bharti and Khurana, 2003; Shikazono et al., 2003; Baxter et al., 2005; Pourcel et al., 2005; Routaboul et al., 2005; L. Pourcel, unpublished).

\begin{tabular}{|c|c|c|c|c|}
\hline \multicolumn{3}{|c|}{ SEED } & PLANT & \multirow[t]{2}{*}{ Mutant (or WT) } \\
\hline PAs & Flavonols & & & \\
\hline+ & + & - & + & $\mathrm{WT}, t t 7^{\mathrm{a}}, t t 10^{\mathrm{b}}$ \\
\hline- & + & - & + & $\begin{array}{l}t t 1, t t 2, t t 9, t t 12, t t 13, t t 15, t t 16 \\
t t g 2, a h a 10, t d s 1, t d s 3, t d s 5, t d s 6\end{array}$ \\
\hline - & + & - & - & $\begin{array}{l}t t 3, t t 8, t t 17, t t 18^{c}, t t 19^{b d}, t t g 1, \\
t d s 2\end{array}$ \\
\hline- & - & - & - & $t t 4, t t 5, t t 6$ \\
\hline - & + & + & + & ban \\
\hline+ & - & - & + & fls 1 \\
\hline
\end{tabular}

${ }^{\mathrm{a}}$ Flavonols and anthocyanins in $t t 7$ are kaempferol derivatives in place of quercetin derivatives

${ }^{\mathrm{b}}$ Seeds brownish with storage time

${ }^{\mathrm{c}}$ Allelic to $t t 11$ and $t d s 4$

${ }^{\mathrm{d}}$ Allelic to $t t 14$ 


\section{REFERENCES}

Abrahams, S., Lee, E., Walker, A. R., Tanner, G. J., Larkin, P. J. and Ashton, A. R. (2003) The Arabidopsis TDS4 gene encodes leucoanthocyanidin dioxygenase (LDOX) and is essential for proanthocyanidin synthesis and vacuole development, Plant Journal, 35(5), 624-636.

Abrahams, S., Tanner, G. J., Larkin, P. J. and Ashton, A. R. (2002) Identification and biochemical characterization of mutants in the proanthocyanidin pathway in Arabidopsis, Plant Physiology, 130(2), 561-576.

Albert, S., Delseny, M. and Devic, M. (1997) BANYULS, a novel negative regulator of flavonoid biosynthesis in the Arabidopsis seed coat, Plant Journal, 11(2), 289-299.

Alerding, A. B., Owens, D. K., Westwood, J. H. and Winkel, B. S. J. (2005) Flavonol synthases in Arabidopsis: gene-specific responses to developmental and biotic signals, In Poster Abstract $n^{\circ} 583$ - Proceedings of the 16th International Conference on Arabidopsis Research, University of Wisconsin, Madison, USA.

Ali-Rachedi, S., Bouinot, D., Wagner, M. H., Bonnet, M., Sotta, B., Grappin, P. and Jullien, M. (2004) Changes in endogenous abscisic acid levels during dormancy release and maintenance of mature seeds: studies with the Cape Verde Islands ecotype, the dormant model of Arabidopsis thaliana, Planta, 219(3), 479-488.

Alonso-Blanco, C., Bentsink, L., Hanhart, C. J., Blankestijn-de Vries, H. and Koornneef, M. (2003) Analysis of natural allelic variation at seed dormancy loci of Arabidopsis thaliana, Genetics, 164(2), 711-729.

Angenent, G. C. and Colombo, L. (1996) Molecular control of ovule development, Trends in Plant Science, 1(7), 228-232.

Atanassova, B., Shtereva, L., Georgieva, Y. and Balatcheva, E. (2004) Study on seed coat morphology and histochemistry in three anthocyaninless mutants in tomato 
(Lycopersicon esculentum Mill.) in relation to their enhanced germination, Seed Science and Technology, 32(1), 79-90.

Atanassova, B., Shtereva, L. and Molle, E. (1997a) Effect of three anthocyaninless genes on germination in tomato (Lycopersicon esculentum Mill) .1. Seed germination under optimal conditions, Euphytica, 95(1), 89-98.

Atanassova, B., Shtereva, L. and Molle, E. (1997b) Effect of three anthocyaninless genes on germination in tomato (Lycopersicon esculentum Mill.) .2. Seed germination under stress conditions, Euphytica, 97(1), 31-38.

Aveling, T. A. S. and Powell, A. A. (2005) Effect of seed storage and seed coat pigmentation on susceptibility of cowpeas to pre-emergence damping-off, Seed Science and Technology, 33(2), 461-470.

Barthe, P., Garello, G., Bianco-Trinchant, J. and le Page-Degivry, M. T. (2000) Oxygen availability and ABA metabolism in Fagus sylvatica seeds, Plant Growth Regulation, 30(2), 185-191.

Basile, A., Sorbo, S., Lopez-Saez, J. A. and Cobianchi, R. C. (2003) Effects of seven pure flavonoids from mosses on germination and growth of Tortula muralis HEDW. (Bryophyta) and Raphanus sativus L. (Magnoliophyta), Phytochemistry, 62(7), 11451151.

Baud, S., Boutin, J. P., Miquel, M., Lepiniec, L. and Rochat, C. (2002) An integrated overview of seed development in Arabidopsis thaliana ecotype WS, Plant Physiology and Biochemistry, 40(2), 151-160.

Baudry, A., Heim, M. A., Dubreucq, B., Caboche, M., Weisshaar, B. and Lepiniec, L. (2004) TT2, TT8, and TTG1 synergistically specify the expression of BANYULS and proanthocyanidin biosynthesis in Arabidopsis thaliana, Plant Journal, 39(3), 366-380. 
Baxter, I. R., Young, J. C., Armstrong, G., Foster, N., Bogenschutz, N., Cordova, T., Peer, W. A., Hazen, S. P., Murphy, A. S. and Harper, J. F. (2005) A plasma membrane $\mathrm{H}^{+}$ATPase is required for the formation of proanthocyanidins in the seed coat endothelium of Arabidopsis thaliana, Proceedings of the National Academy of Sciences of the United States of America USA, 102(7), 2649-2654.

Becker, A., Kaufmann, K., Freialdenhoven, A., Vincent, C., Li, M. A., Saedler, H. and Theissen, G. (2002) A novel MADS-box gene subfamily with a sister-group relationship to class B floral homeotic genes, Molecular Genetics and Genomics, 266(6), 942-950.

Beeckman, T., De Rycke, R., Viane, R. and Inzé, D. (2000) Histological study of seed coat development in Arabidopsis thaliana, Journal of Plant Research, 113(1110), 139-148.

Bentsink, L. and Koornneef, M. (2002) Seed dormancy and germination, In The Arabidopsis Book, (Eds, Somerville, C. R. and Meyerowitz, E. M.) American Society of Plant Biologists, Rockville, MD (doi/10.1199/tab.ooog, http://www.aspb.org/publications/arabidopsis/), pp. DOI 10.1199 tab.0050.

Bewley, J. D. (1997) Seed germination and dormancy, Plant Cell, 9(7), 1055-1066.

Bewley, J. D. and Black, M. (1994) Seeds: physiology of development and germination, Plenum Press, New York and London.

Bharti, A. K. and Khurana, J. P. (2003) Molecular characterization of transparent testa (tt) mutants of Arabidopsis thaliana (ecotype Estland) impaired in flavonoid biosynthetic pathway, Plant Science, 165(6), 1321-1332.

Boesewinkel, F. D. and Bouman, F. (1995) The seed: structure and function, In Seed development and germination, (Eds, Kigel, J. and Galili, G.) Marcel Dekker, Inc., pp. $1-24$. 
Bouman, F. (1975) Integument initiation and testa development in some Cruciferae, Botanical Journal of the Linnean Society, 70(3), 213-229.

Buta, J. G. and Lusby, W. R. (1986) Catechins as germination and growth inhibitors in Lespedeza seeds, Phytochemistry, 25(1), 93-95.

Capeleti, I., Ferrarese, M. L. L., Krzyzanowski, F. C. and Ferrarese, O. (2005) A new procedure for quantification of lignin in soybean (Glycine max (L.) Merrill) seed coat and their relationship with the resistance to mechanical damage, Seed Science and Technology, 33(2), 511-515.

Chen, F., Nonogaki, H. and Bradford, K. J. (2002) A gibberellin-regulated xyloglucan endotransglycosylase gene is expressed in the endosperm cap during tomato seed germination, Journal of Experimental Botany, 53(367), 215-223.

Clerkx, E. J. M., Blankestijn-De Vries, H., Ruys, G. J., Groot, S. P. C. and Koornneef, M. (2004) Genetic differences in seed longevity of various Arabidopsis mutants, Physiologia Plantarum, 121(3), 448-461.

Corcoran, M. R., Geissman, T. A. and Phinney, B. O. (1972) Tannins as gibberellin antagonists, Plant Physiology, 49(3), 323-330.

Cutillo, F., D'Abrosca, B., DellaGreca, M., Fiorentino, A. and Zarrelli, A. (2003) Lignans and neolignans from Brassica fruticulosa: Effects on seed germination and plant growth, Journal of Agricultural and Food Chemistry, 51(21), 6165-6172.

Debeaujon, I. and Koornneef, M. (2000) Gibberellin requirement for Arabidopsis seed germination is determined both by testa characteristics and embryonic abscisic acid, Plant Physiology, 122(2), 415-424.

Debeaujon, I., Léon-Kloosterziel, K. M. and Koornneef, M. (2000) Influence of the testa on seed dormancy, germination, and longevity in Arabidopsis, Plant Physiology, 122(2), 403-413. 
Debeaujon, I., Nesi, N., Perez, P., Devic, M., Grandjean, O., Caboche, M. and Lepiniec, L. (2003) Proanthocyanidin-accumulating cells in Arabidopsis testa: Regulation of differentiation and role in seed development, Plant Cell, 15(11), 2514-2531.

Debeaujon, I., Peeters, A. J., Léon-Kloosterziel, K. M. and Koornneef, M. (2001) The TRANSPARENT TESTA12 gene of Arabidopsis encodes a multidrug secondary transporter-like protein required for flavonoid sequestration in vacuoles of the seed coat endothelium, Plant Cell, 13(4), 853-871.

Devic, M., Guilleminot, J., Debeaujon, I., Bechtold, N., Bensaude, E., Koornneef, M., Pelletier, G. and Delseny, M. (1999) The BANYULS gene encodes a DFR-like protein and is a marker of early seed coat development, Plant Journal, 19(4), 387-398.

Diederichsen, A. and Jones-Flory, L. L. (2005) Accelerated aging tests with seeds of 11 flax (Linum usitatissimum) cultivars, Seed Science and Technology, 33(2), 419-429.

Dixon, R. A., Xie, D. Y. and Sharma, S. B. (2005) Proanthocyanidins - a final frontier in flavonoid research?, New Phytologist, 165(1), 9-28.

Downie, A. B., Dirk, L. M. A., Xu, Q. L., Drake, J., Zhang, D. Q., Dutt, M., Butterfield, A., Geneve, R. R., Corum, J. W., Lindstrom, K. G. and Snyder, J. C. (2004) A physical, enzymatic, and genetic characterization of perturbations in the seeds of the brownseed tomato mutants, Journal of Experimental Botany, 55(399), 961-973.

Downie, A. B., Zhang, D. Q., Dirk, L. M. A., Thacker, R. R., Pfeiffer, J. A., Drake, J. L., Levy, A. A., Butterfield, A., Buxton, J. W. and Synder, J. C. (2003) Communication between the maternal testa and the embryo and/or endosperm affect testa attributes in tomato, Plant Physiology, 133(1), 145-160.

Dubreucq, B., Berger, N., Vincent, E., Boisson, M., Pelletier, G., Caboche, M. and Lepiniec, L. (2000) The Arabidopsis AtEPR1 extensin-like gene is specifically expressed in endosperm during seed germination, Plant Journal, 23(5), 643-652. 
Edelstein, M., Corbineau, F., Kigel, J. and Nerson, H. (1995) Seed coat structure and oxygen availability control low-temperature germination of melon (Cucumis melo) Seeds, Physiologia Plantarum, 93(3), 451-456.

Flintham, J. E. (2000) Different genetic components control coat-imposed and embryoimposed dormancy in wheat, Seed Science Research, 10(1), 43-50.

Focks, N., Sagasser, M., Weisshaar, B. and Benning, C. (1999) Characterization of tt15, a novel transparent testa mutant of Arabidopsis thaliana (L.) Heynh, Planta, 208(3), $352-357$.

Gale, M. D., Flintham, J. E. and Devos, K. M. (2002) Cereal comparative genetics and preharvest sprouting, Euphytica, 126(1), 21-25.

Garcia, D., Fitz Gerald, J. N. and Berger, F. (2005) Maternal control of integument cell elongation and zygotic control of endosperm growth are coordinated to determine seed size in Arabidopsis, Plant Cell, 17(1), 52-60.

Garcia, D., Saingery, V., Chambrier, P., Mayer, U., Jürgens, G. and Berger, F. (2003) Arabidopsis haiku mutants reveal new controls of seed size by endosperm, Plant Physiology, 131(4), 1661-1670.

Gatford, K. T., Eastwood, R. F. and Halloran, G. M. (2002) Germination inhibitors in bracts surrounding the grain of Triticum tauschii, Functional Plant Biology, 29(7), 881-890.

Gijzen, M., Kuflu, K., Qutob, D. and Chernys, J. T. (2001) A class I chitinase from soybean seed coat, Journal of Experimental Botany, 52(365), 2283-2289.

Gillikin, J. W. and Graham, J. S. (1991) Purification and developmental analysis of the major anionic peroxidase from the seed coat of Glycine max, Plant Physiology, 96(1), 214220.

Goto, N. (1985) A mucilage polysaccharide secreted from testa of Arabidopsis thaliana, Arabidopsis Information Service, 22, 143-145. 
Green, F. B. and Corcoran, M. R. (1975) Inhibitory action of five tannins on growth induced by several gibberellins, Plant Physiology, 56(6), 801-806.

Griffen, L. R., Wilczek, A. M. and Bazzaz, F. A. (2004) UV-B affects within-seed biomass allocation and chemical provisioning, New Phytologist, 162(1), 167-171.

Groot, S. P. C., Kieliszewska-Rokicka, B., Vermeer, E. and Karssen, C. M. (1988) Gibberellin-induced hydrolysis of endosperm cell walls in gibberellin-deficient tomato seeds prior to radicle protrusion, Planta, 174(4), 500-504.

Gu, X. Y., Kianian, S. F., Hareland, G. A., Hoffer, B. L. and Foley, M. E. (2005) Genetic analysis of adaptive syndromes interrelated with seed dormancy in weedy rice (Oryza sativa), Theoretical and Applied Genetics, 110(6), 1108-1118.

Gutterman, Y. (2000) Maternal effects on seeds during development, In Seeds: the ecology of regeneration in plant communities, 2nd edition, (Ed, Fenner, M.) CAB International 2000, pp. 59-84.

Halloin, J. M. (1982) Localization and changes in catechin and tannins during development and ripening of cottonseed, New Phytologist, 90(4), 641-657.

Haughn, G. and Chaudhury, A. (2005) Genetic analysis of seed coat development in Arabidopsis, Trends in Plant Science, 10(10), 472-477.

Himi, E., Mares, D. J., Yanagisawa, A. and Noda, K. (2002) Effect of grain colour gene (R) on grain dormancy and sensitivity of the embryo to abscisic acid (ABA) in wheat, Journal of Experimental Botany, 53(374), 1569-1574.

Himi, E., Nisar, A. and Noda, K. (2005) Colour genes (R and Rc) for grain and coleoptile upregulate flavonoid biosynthesis genes in wheat, Genome, 48(4), 747-754.

Himi, E. and Noda, K. (2005) Red grain colour gene (R) of wheat is a Myb-type transcription factor, Euphytica, 143(3), 239-242. 
Hood, E. E., Bailey, M. R., Beifuss, K., Magallanes-Lundback, M., Horn, M. E., Callaway, E., Drees, C., Delaney, D. E., Clough, R. and Howard, J. A. (2003) Criteria for highlevel expression of a fungal laccase gene in transgenic maize, Plant Biotechnology Journal, 1(2), 129-140.

Islam, F. M. A., Rengifo, J., Redden, R. J., Basford, K. E. and Beebe, S. E. (2003) Association between seed coat polyphenolics (tannins) and disease resistance in common bean, Plant Foods for Human Nutrition, 58(4), 285-297.

Iwanowska, A., Tykarska, T., Kuras, M. and Zobel, A. M. (1994) Localization of phenolic compounds in the covering tissues of the embryo of Brassica napus (L.) during different stages of embryogenesis and seed maturation, Annals of Botany, 74(4), 313320.

Job, C., Rajjou, L., Lovigny, Y., Belghazi, M. and Job, D. (2005) Patterns of protein oxidation in Arabidopsis seeds and during germination, Plant Physiology, 138(2), 790-802.

Johnson, C. S., Kolevski, B. and Smyth, D. R. (2002) TRANSPARENT TESTA GLABRA2, a trichome and seed coat development gene of Arabidopsis, Encodes a WRKY transcription factor, Plant Cell, 14(6), 1359-1375.

Kantar, F., Pilbeam, C. J. and Hebblethwaite, P. D. (1996) Effect of tannin content of faba bean (Vicia faba) seed on seed vigour, germination and field emergence, Annals of Applied Biology, 128(1), 85-93.

Karssen, C. M. (2002) Germination, dormancy and red tape, Seed Science Research, 12(4), 203-216.

Kelly, K. M., Staden, J. v. and Bell, W. E. (1992) Seed coat structure and dormancy, Plant Growth Regulation, 11(3), 213-222.

Kermode, A. R. (1995) Regulatory mechanisms in the transition from seed development to germination: interactions between the embryo and the seed environment, In Seed 
development and germination, (Eds, Kigel, J. and Galili, G.) Marcel Dekker, Inc., New-York, pp. 273-332.

Kim, Y. C., Nakajima, M., Nakayama, A. and Yamaguchi, I. (2005) Contribution of gibberellins to the formation of Arabidopsis seed coat through starch degradation, Plant and Cell Physiology, 46(8), 1317-1325.

Kitamura, S., Shikazono, N. and Tanaka, A. (2004) TRANSPARENT TESTA 19 is involved in the accumulation of both anthocyanins and proanthocyanidins in Arabidopsis, Plant Journal, 37(1), 104-114.

Koornneef, M. (1981) The complex syndrome of ttg mutants, Arabidopsis Information Service, 18, 45-51.

Koornneef, M. (1990) Mutations affecting the testa colour in Arabidopsis, Arabidopsis Information Service, 27, 1-4.

Koornneef, M., Bentsink, L. and Hilhorst, H. (2002) Seed dormancy and germination, Current Opinion in Plant Biology, 5(1), 33-36.

Kwak, S. S., Kamiya, Y., Sakurai, A. and Takahashi, N. (1988) Isolation of a gibberellin biosynthesis inhibitor from testas of Phaseolus vulgaris L, Agricultural and Biological Chemistry, 52(1), 149-152.

Lattanzio, V., Terzano, R., Cicco, N., Cardinali, A., Venere, D. d. and Linsalata, V. (2005) Seed coat tannins and bruchid resistance in stored cowpea seeds, Journal of the Science of Food and Agriculture, 85(5), 839-846.

Legesse, N. and Powell, A. A. (1992) Comparisons of water uptake and imbibition damage in 11 Cowpea Cultivars, Seed Science and Technology, 20(1), 173-180.

Legesse, N. and Powell, A. A. (1996) Relationship between the development of seed coat pigmentation, seed coat adherence to the cotyledons and the rate of imbibition during the maturation of grain legumes, Seed Science and Technology, 24(1), 23-32. 
Lenoir, C., Corbineau, F. and Côme, D. (1986) Barley (Hordeum vulgare) seed dormancy as related to glumella characteristics, Physiologia Plantarum, 68, 301-307.

Léon-Kloosterziel, K. M., Keijzer, C. J. and Koornneef, M. (1994) A seed shape mutant of Arabidopsis that is affected in integument development, Plant Cell, 6(3), 385-392.

Lepiniec, L., Debeaujon, I., Routaboul, J.-M., Baudry, A., Pourcel, L., Nesi, N. and Caboche, M. (2006) Genetics and biochemistry of seed flavonoids, Annual Review of Plant Biology, in press.

Lepiniec, L., Devic, M. and Berger, F. (2005) Genetic and molecular control of seed development in Arabidopsis, In Plant Functional Genomics, (Ed, Leister, D.) Haworth Press, Inc., pp. 511-564.

Leubner-Metzger, G. (2002) Seed after-ripening and over-expression of class I beta-1,3glucanase confer maternal effects on tobacco testa rupture and dormancy release, Planta, 215(6), 959-968.

Manz, B., Muller, K., Kucera, B., Volke, F. and Leubner-Metzger, G. (2005) Water uptake and distribution in germinating tobacco seeds investigated in vivo by nuclear magnetic resonance imaging, Plant Physiology, 138(3), 1538-1551.

Marbach, I. and Mayer, A. M. (1974) Permeability of seed coats to water as related to drying conditions and metabolism of phenolics, Plant Physiology, 54(6), 817-820.

Marbach, I. and Mayer, A. M. (1975) Changes in catechol oxidase and permeability to water in seed coats of Pisum elatius during seed development and maturation, Plant Physiology, 56(1), 93-96.

Mares, D., Mrva, K., Tan, M. K. and Sharp, P. (2002) Dormancy in white-grained wheat: Progress towards identification of genes and molecular markers, Euphytica, 126(1), 47-53. 
Marles, M. A., Ray, H. and Gruber, M. Y. (2003) New perspectives on proanthocyanidin biochemistry and molecular regulation, Phytochemistry, 64(2), 367-83.

Marles, M. A. S. and Gruber, M. Y. (2004) Histochemical characterisation of unextractable seed coat pigments and quantification of extractable lignin in the Brassicaceae, Journal of the Science of Food and Agriculture, 84(3), 251-262.

Matilla, A., Gallardo, M. and Puga-Hermida, M. I. (2005) Structural, physiological and molecular aspects of heterogeneity in seeds: a review, Seed Science Research, 15(2), 63-76.

Mohamed-Yasseen, Y., Barringer, S. A., Splittstoesser, W. E. and Costanza, S. (1994) The role of seed coats in seed viability, Botanical Review, 60(4), 426-439.

Naczk, M., Amarowicz, R., Sullivan, A. and Shahidi, F. (1998) Current research developments on polyphenolics of rapeseed/canola: a review, Food Chemistry, 62(4), 489-502.

Nakaune, S., Yamada, K., Kondo, M., Kato, T., Tabata, S., Nishimura, M. and HaraNishimura, I. (2005) A vacuolar processing enzyme, delta VPE, is involved in seed coat formation at the early stage of seed development, Plant Cell, 17(3), 876-887.

Nesi, N., Debeaujon, I., Jond, C., Pelletier, G., Caboche, M. and Lepiniec, L. (2000) The TT8 gene encodes a basic helix-loop-helix domain protein required for expression of $D F R$ and $B A N$ genes in Arabidopsis siliques, Plant Cell, 12(10), 1863-1878.

Nesi, N., Debeaujon, I., Jond, C., Stewart, A. J., Jenkins, G. I., Caboche, M. and Lepiniec, L. (2002) The TRANSPARENT TESTA16 locus encodes the ARABIDOPSIS BSISTER MADS domain protein and is required for proper development and pigmentation of the seed coat, Plant Cell, 14(10), 2463-2479. 
Nesi, N., Jond, C., Debeaujon, I., Caboche, M. and Lepiniec, L. (2001) The Arabidopsis TT2 gene encodes an R2R3 MYB domain protein that acts as a key determinant for proanthocyanidin accumulation in developing seed, Plant Cell, 13(9), 2099-2114.

Olsen, O. A. (2004) Nuclear endosperm development in cereals and Arabidopsis thaliana, Plant Celll, 16 Suppl, S214-227.

Porter, N. G. and Wareing, P. F. (1974) The role of the oxygen permeability of the seed coat in the dormancy of seeds of Xanthium pennsylvanicum Wallr., Journal of Experimental Botany, 25(86), 583-594.

Pourcel, L., Routaboul, J.-M., Kerhoas, L., Caboche, M., Lepiniec, L. and Debeaujon, I. (2005) TRANSPARENT TESTA10 encodes a laccase-like enzyme involved in oxidative polymerization of flavonoids in Arabidopsis seed coat., Plant Cell, 17(11), 2966-2980.

Puga-Hermida, M. I., Gallardo, M., Rodriguez-Gacio, M. D. and Matilla, A. J. (2003) The heterogeneity of turnip-tops (Brassica rapa) seeds inside the silique affects germination, the activity of the final step of the ethylene pathway, and abscisic acid and polyamine content, Functional Plant Biology, 30(7), 767-775.

Rajjou, L., Gallardo, K., Debeaujon, I., Vandekerckhove, J., Job, C. and Job, D. (2004) The effect of alpha-amanitin on the Arabidopsis seed proteome highlights the distinct roles of stored and neosynthesized mRNAs during germination, Plant Physiology, 134(4), 1598-1613.

Reigosa, M. J., Souto, X. C. and Gonzalez, L. (1999) Effect of phenolic compounds on the germination of six weeds species, Plant Growth Regulation, 28(2), 83-88.

Ren, C. W. and Kermode, A. R. (1999) Analyses to determine the role of the megagametophyte and other seed tissues in dormancy maintenance of yellow cedar (Chamaecyparis nootkatensis) seeds: morphological, cellular and physiological 
changes following moist chilling and during germination, Journal of Experimental Botany, 50(337), 1403-1419.

Rice-Evans, C. A., Miller, J. and Paganga, G. (1997) Antioxidant properties of phenolic compounds, Trends in Plant Science, 2(4), 152-159.

Routaboul, J.-M., Kerhoas, L., Debeaujon, I., Pourcel, L., Caboche, M., Einhorn, J. and Lepiniec, L. (2005) Flavonoid diversity and biosynthesis in seed of Arabidopsis thaliana, Planta, in press.

Sagasser, M., Lu, G., Hahlbrock, K. and Weisshaar, B. (2002) A. thaliana TRANSPARENT TESTA 1 is involved in seed coat development and defines the WIP subfamily of plant zinc finger proteins, Genes \& Development, 16(1), 138-149.

Salaita, L., Kar, R. K., Majee, M. and Downie, A. B. (2005) Identification and characterization of mutants capable of rapid seed germination at 10 degrees $\mathrm{C}$ from activation-tagged lines of Arabidopsis thaliana, Journal of Experimental Botany, 56(418), 2059-2069.

Scalbert, A. (1991) Antimicrobial Properties of Tannins, Phytochemistry, 30(12), 3875-3883.

Schneitz, K., Hulskamp, M. and Pruitt, R. E. (1995) Wild-type ovule development in Arabidopsis thaliana - a light microscope study of cleared whole-mount tissue, Plant Journal, 7(5), 731-749.

Serrato-Valenti, G., Cornara, L., Ghisellini, P. and Ferrando, M. (1994) Testa structure and histochemistry related to water uptake in Leucaena leucocephala Lam (Dewit), Annals of Botany, 73(5), 531-537.

Sharma, S. B. and Dixon, R. A. (2005) Metabolic engineering of proanthocyanidins by ectopic expression of transcription factors in Arabidopsis thaliana, Plant Journal, 44(1), 62-75. 
Shikazono, N., Yokota, Y., Kitamura, S., Suzuki, C., Watanabe, H., Tano, S. and Tanaka, A. (2003) Mutation rate and novel $t t$ mutants of Arabidopsis thaliana induced by carbon, Genetics, 163(4), 1449-1455.

Shirley, B. W., Kubasek, W. L., Storz, G., Bruggemann, E., Koornneef, M., Ausubel, F. M. and Goodman, H. M. (1995) Analysis of Arabidopsis mutants deficient in flavonoid biosynthesis, Plant Journal, 8(5), 659-671.

Skadhauge, B., Thomsen, K. K. and Von Wettstein, D. (1997) The role of the barley testa layer and its flavonoid content in resistance to Fusarium infections, Hereditas, 126(2), 147-160.

Stafford, H. A. (1974) The metabolism of aromatic compounds, Annual Review of Plant Physiology, 25, 459-486.

Stafford, H. A. (1988) Proanthocyanidins and the lignin connection, Phytochemistry, 27(1), 16.

Tanner, G. J., Francki, K. T., Abrahams, S., Watson, J. M., Larkin, P. J. and Ashton, A. R. (2003) Proanthocyanidin biosynthesis in plants. Purification of legume leucoanthocyanidin reductase and molecular cloning of its cDNA, Journal of Biological Chemistry, 278(34), 31647-31656.

Terskikh, V. V., Feurtado, J. A., Ren, C. W., Abrams, S. R. and Kermode, A. R. (2005) Water uptake and oil distribution during imbibition of seeds of western white pine (Pinus monticola Dougl. ex D. Don) monitored in vivo using magnetic resonance imaging, Planta, 221(1), 17-27.

Vaughan, J. G. and Whitehouse, J. M. (1971) Seed structure and the taxonomy of the Cruciferae, Botanical Journal of the Linnean Society, 64(4), 383-409.

Walker, A. R., Davison, P. A., Bolognesi-Winfield, A. C., James, C. M., Srinivasan, N., Blundell, T. L., Esch, J. J., Marks, M. D. and Gray, J. C. (1999) The TRANSPARENT 
TESTA GLABRA1 locus, which regulates trichome differentiation and anthocyanin biosynthesis in Arabidopsis, encodes a WD40 repeat protein, Plant Cell, 11(7), 13371350.

Walters, C. (1998) Understanding the mechanisms and kinetics of seed aging, Seed Science Research, 8(2), 223-244.

Wan, L., Xia, Q., Qiu, X. and Selvaraj, G. (2002) Early stages of seed development in Brassica napus: a seed coat-specific cysteine proteinase associated with programmed cell death of the inner integument, Plant Journal, 30(1), 1-10.

Weidner, S., Krupa, U., Amarowicz, R., Karamac, M. and Abe, S. (2002) Phenolic compounds in embryos of triticale caryopses at different stages of development and maturation in normal environment and after dehydration treatment, Euphytica, 126(1), 115-122.

Werker, E. (1980/81) Seed dormancy as explained by the anatomy of embryo envelops, Israel Journal of Botany, 29, 22-44.

Werker, E. (1997) Seed anatomy - Encyclopedia of Plant Anatomy, Gebrüder Borntraeger 424 pp, Berlin.

Werker, E., Marbach, I. and Mayer, A. M. (1979) Relation between the anatomy of the testa, water permeability and the presence of phenolics in the genus Pisum, Annals of Botany, 43(6), 765-771.

Western, T. L., Skinner, D. J. and Haughn, G. W. (2000) Differentiation of mucilage secretory cells of the Arabidopsis seed coat, Plant Physiology, 122(2), 345-355.

Windsor, J. B., Symonds, V. V., Mendenhall, J. and Lloyd, A. M. (2000) Arabidopsis seed coat development: morphological differentiation of the outer integument, Plant Journal, 22(6), 483-493. 
Winkel-Shirley, B. (1998) Flavonoids in seeds and grains: physiological function, agronomic importance and the genetics of biosynthesis, Seed Science Research, 8(4), 415-422.

Winkel-Shirley, B. (2002a) Biosynthesis of flavonoids and effects of stress, Current Opinion in Plant Biology, 5(3), 218-223.

Winkel-Shirley, B. (2002b) A mutational approach to dissection of flavonoid biosynthesis in Arabidopsis, In Phytochemistry in the genomics and post-genomics eras, Vol. Recent Advances in Phytochemistry 36 (Eds, Romeo, J. T. and Dixon, R. A.) PergamonElsevier Science, pp. 95-110.

Wisman, E., Hartmann, U., Sagasser, M., Baumann, E., Palme, K., Hahlbrock, K., Saedler, H. and Weisshaar, B. (1998) Knock-out mutants from an En-1 mutagenized Arabidopsis thaliana population generate phenylpropanoid biosynthesis phenotypes, Proceedings of the National Academy of Sciences of the United States of America USA, 95(21), $12432-12437$.

Wrobel, M., Karamac, M., Amarowicz, R., Frqczek, E. and Weidner, S. (2005) Metabolism of phenolic compounds in Vitis riparia seeds during stratification and during germination under optimal and low temperature stress conditions, Acta Physiologiae Plantarum, 27(3A), 313-320.

Wyatt, J. E. (1977) Seed coat and water absorption properties of seed of near-isogenic snap bean lines differing in seed coat color, Journal of the American Society for Horticultural Science, 102(4), 478-480.

Xie, D. Y., Sharma, S. B. and Dixon, R. A. (2004) Anthocyanidin reductases from Medicago truncatula and Arabidopsis thaliana, Archives of Biochemistry and Biophysics, 422(1), 91-102. 
Xie, D. Y., Sharma, S. B., Paiva, N. L., Ferreira, D. and Dixon, R. A. (2003) Role of anthocyanidin reductase, encoded by $B A N Y U L S$ in plant flavonoid biosynthesis, Science, 299(5605), 396-399.

Yamaguchi, S., Smith, M. W., Brown, R. G. S., Kamiya, Y. and Sun, T. P. (1998) Phytochrome regulation and differential expression of gibberellin 3 beta-hydroxylase genes in germinating Arabidopsis seeds, Plant Cell, 10(12), 2115-2126.

Zee, S. Y. and O'Brien (1970) Studies on the ontogeny of the pigment strand in the caryopsis of wheat, Australian Journal of Biological Sciences, 23(6), 1153-1171.

Zobel, A., Kuras, M. and Tykarska, T. (1989) Cytoplasmic and apoplastic location of phenolic compounds in the covering tissue of the Brassica napus radicles between embryogenesis and germination, Annals of Botany, 64(2), 149-157.

\section{FIGURE LEGENDS}

\section{Fig. 3.1 Testa structure and flavonoid localization in Arabidopsis seed.}

(A) Anatomy of a developing seed at the heart stage of embryo development (longitudinal section). Cells accumulating either proanthocyanidins or flavonols are highlighted in black or gray, respectively. The integument layers are labelled according to Beeckman et al. (2000); the endothelium corresponds to the iil layer (adapted from Pourcel et al., 2005).

(B) Cross section of the mature testa.

c, chalaza; cl, columella; cpt, chalazal proliferating tissue (nucellus); ct, cuticle; cv, central vacuole; cw, cell wall; e, embryo; h, hyaline layer; ii, inner integument; m, micropyle; mu, mucilage; oi, outer integument; pe, peripheral endosperm (aleurone layer); ps, pigment strand; s, suspensor; vb, vascular bundle. Bar $=40 \square \mathrm{m}$ in (A) and $7 \square \mathrm{m}$ in (B). 
Fig. 3.2 Overview of flavonoid biosynthesis and dormancy induction during seed development in Arabidopsis.

Double fertilization results in the formation of a diploid embryo and a triploid endosperm. Embryo organization is completed during the embryogenesis phase. Reserve accumulation and primary dormancy establishment take place mainly during the maturation phase, which is followed by desiccation. Flavonoids (flavonols, proanthocyanidins) are synthesized early during development. During the desiccation phase, proanthocyanidins are oxidized to give brown derivatives that confer mature seed color (adapted from Baud et al., 2002; Bentsink and Koornneef, 2002; Debeaujon et al., 2003; Lepiniec et al., 2005; Pourcel et al., 2005; Routaboul et al., 2005). Daf, days after fertilization.

Fig. 3.3 Interactions between the envelopes and embryo controlling seed dormancy and germination.

Radicle protrusion occurs when embryo growth potential overcomes the constraints imposed by the envelopes. The main mechanisms through which the testa can influence embryo growth potential are mentionned in frames. Hydrolase(s) secreted by the endosperm may contribute the rupture of micropylar endosperm and testa.. Full lines represent an action, and dashed lines, diffusion or leakage. Sharp and blunt arrows stand for a promotive and inhibitory action, respectively. ABA, abscisic acid; GAs, gibberellins; In, inhibitor; Pfr, far red light photoreceptor phytochrome. (Adapted from Bewley and Black, 1994; Debeaujon and Koornneef, 2000; Bentsink and Koornneef, 2002; Leubner-Metzger, 2002).

Fig. 3.4 Flavonoid biosynthetic pathway and the upstream enzymatic steps. 
Flavonoids are plant-specific secondary metabolites derived from 4-coumaroyl-CoA and acetyl coA, formed through the phenylpropanoid pathway and the Krebs cycle, respectively. In Arabidopsis seeds, the flavonoid pathway leads to the formation of two major endproducts: proanthocyanidins (PAs) that become brown after oxidation, and flavonol glycosides (yellow). Anthocyanins (purple) are found only in the banyuls (ban) mutant testa (see Table 3.1.), where they replace PAs. Red phlobaphenes are found in the seed-covering tissues in species such as wheat and rice, and isoflavones are present essentially in Leguminosae (adapted from Winkel-Shirley, 1998; Winkel-Shirley, 2002b; Pourcel et al., 2005; Routaboul et al., 2005; Lepiniec et al., 2006). The dashed arrow indicates that this step takes place in vegetative parts. Enzymes are represented in uppercase and bold letters, the corresponding mutants in lowercase and italics, and the regulatory mutants in brackets. ANR, anthocyanidin reductase; $\mathrm{CE}$, condensing enzyme; $\mathrm{CHI}$, chalcone isomerase; $\mathrm{CHS}$, chalcone synthase; DFR, dihydroflavonol reductase; F3H, flavanone 3-hydroxylase; F3'H, flavanone 3'-hydroxylase; FLS, flavonol synthase; GT, glycosyltransferase; LAC, laccase; LDOX, leucoanthocyanidin dioxygenase; tannin-deficient seed ( $t d s)$; ttg, transparent testa glabra.

Fig. 3.5 Effect of transparent testa mutations on dormancy and germination of Arabidopsis seeds

(A) Effect of dry storage (after-ripening) on dormancy release (adapted from Debeaujon et al., 2000).

(B) Maternal control of seed dormancy in the $t t 2-1$ mutant. The germination behaviors of F1 seed progenies from reciprocal crosses between $t t 2-1$ and WT are shown and compared to WT and the mutant parent. The parent line indicated first in the cross (e.g. "WT" in "WT x tt2-l") was used as a female. The time course of germination after 16-days storage is presented (adapted from Debeaujon et al., 2000). 
(C) Influence of testa mutation on germination behavior of the gibberellin-deficient mutant gal-1. The gal-1 mutation was introduced into a $t t 4-1$ background. The effect of light and cold stratification (pre-chilling) on dormancy breakage and germination of WT, single and double mutants are compared (adapted from Debeaujon and Koornneef, 2000).

(D) Permeability of the testa to GAs. Germination of wild-type seeds was examined in the presence of $100 \square \mathrm{M}$ paclobutrazol (GA biosynthesis inhibitor) and various concentrations of GAs, and compared to the germination of typical transparent testa mutant seeds (tt2-3) and seeds of a transgenic line deprived of proanthocyanidin-producing cells ( $p B A N: B A R N A S E)$ through genetic ablation(see text for details). Non-dormant seeds were used. (Adapted from Debeaujon et al., 2003). 


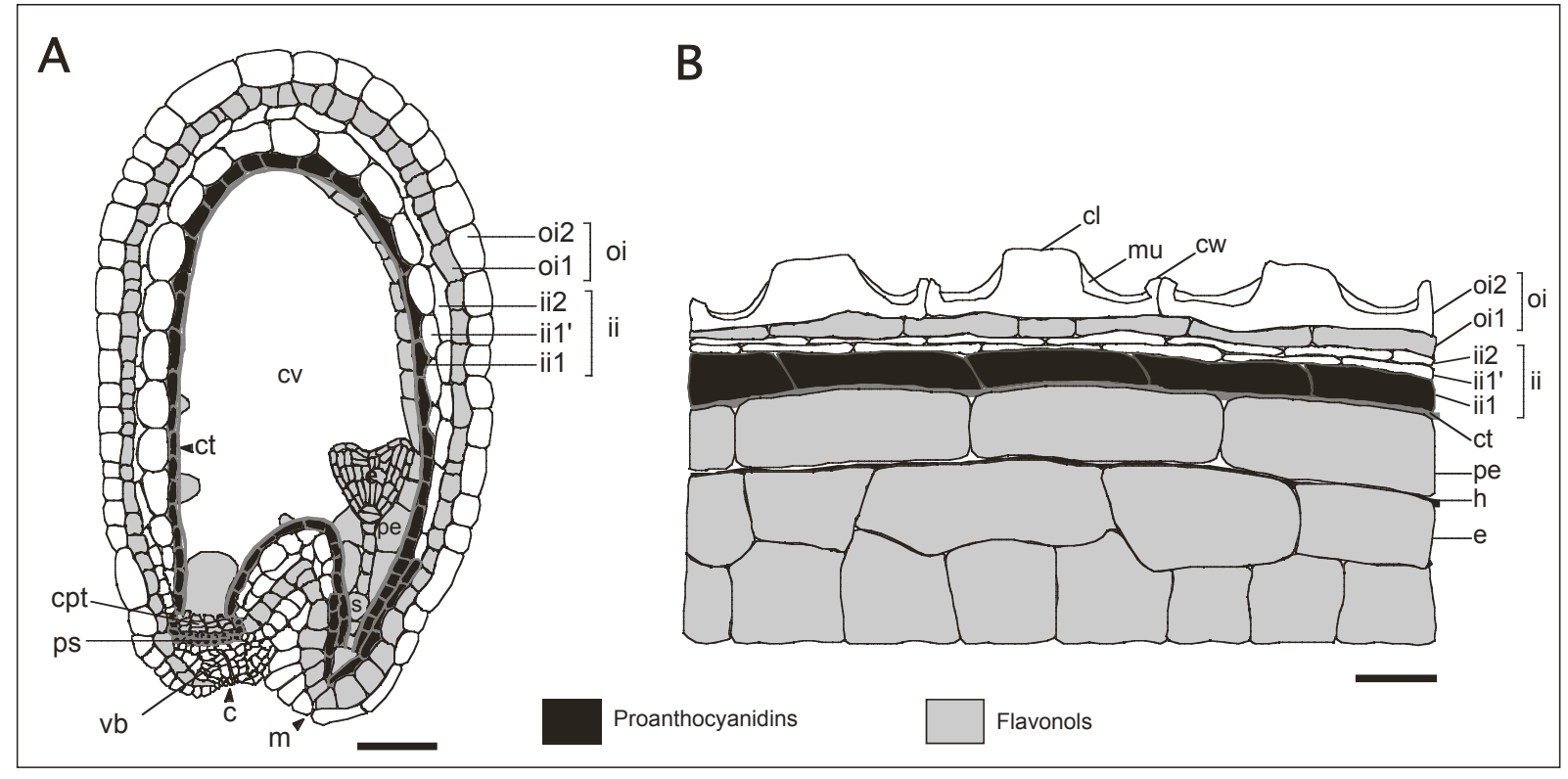


Fig. 3.2

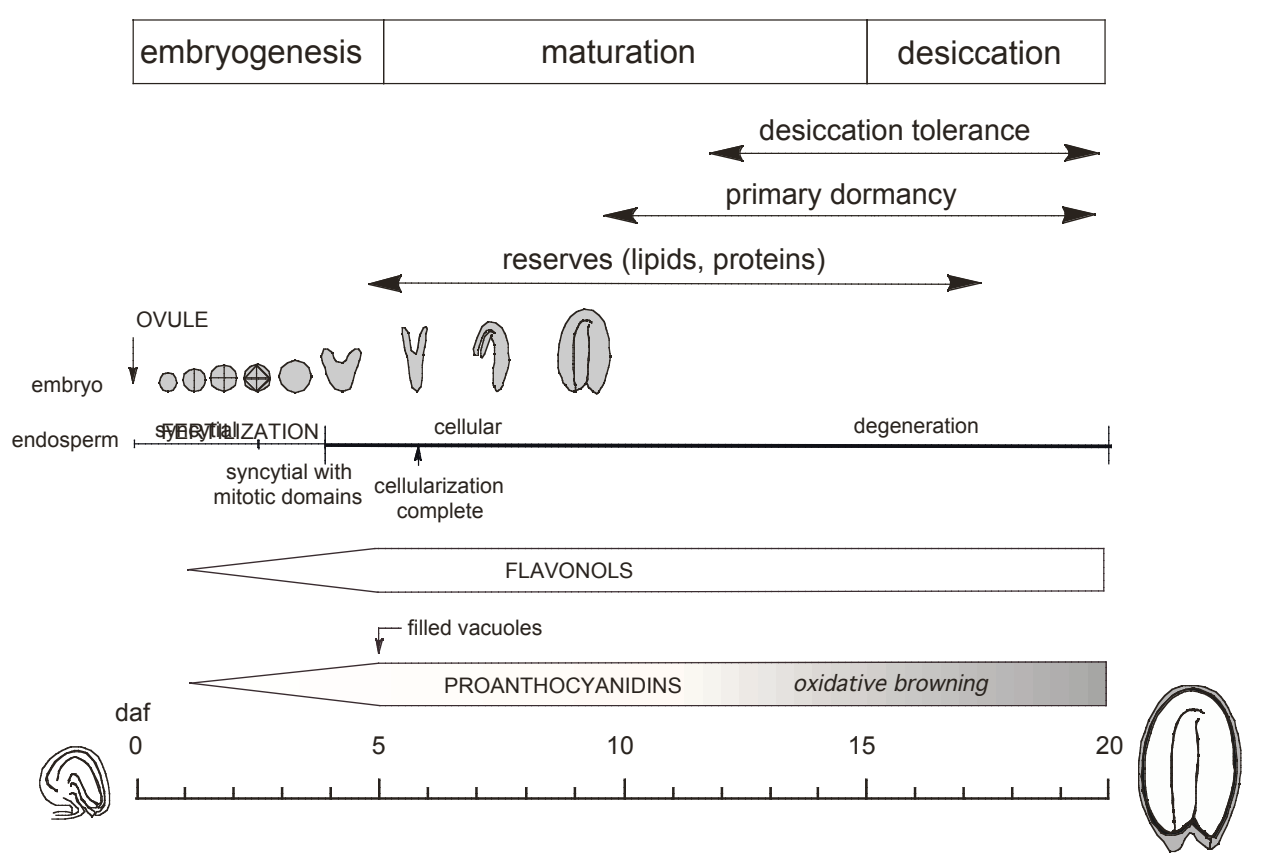


Fig. 3.3

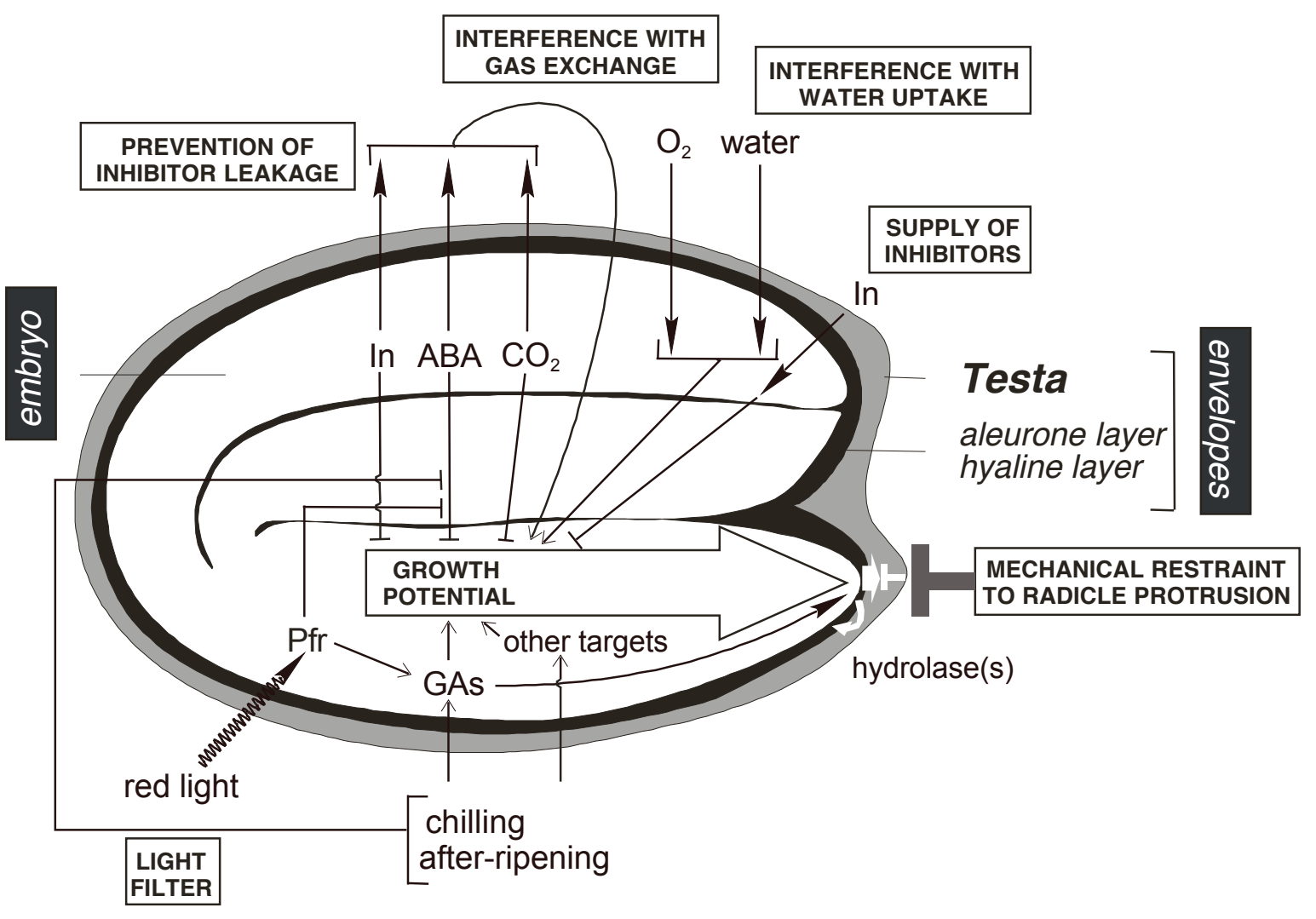


Fig. 3.4

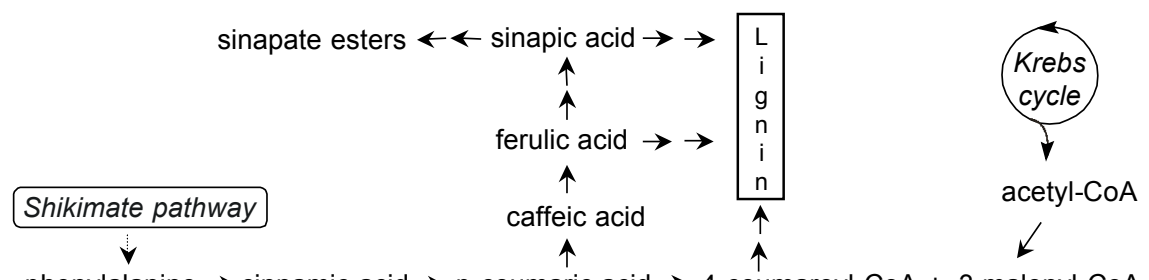

phenylalanine $\rightarrow$ cinnamic acid $\rightarrow$ p-coumaric acid $\rightarrow$ 4-coumaroyl-CoA +3 malonyl-CoA

Phenylpropanoid pathway

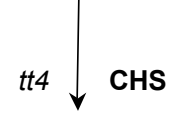

tetrahydroxychalcone

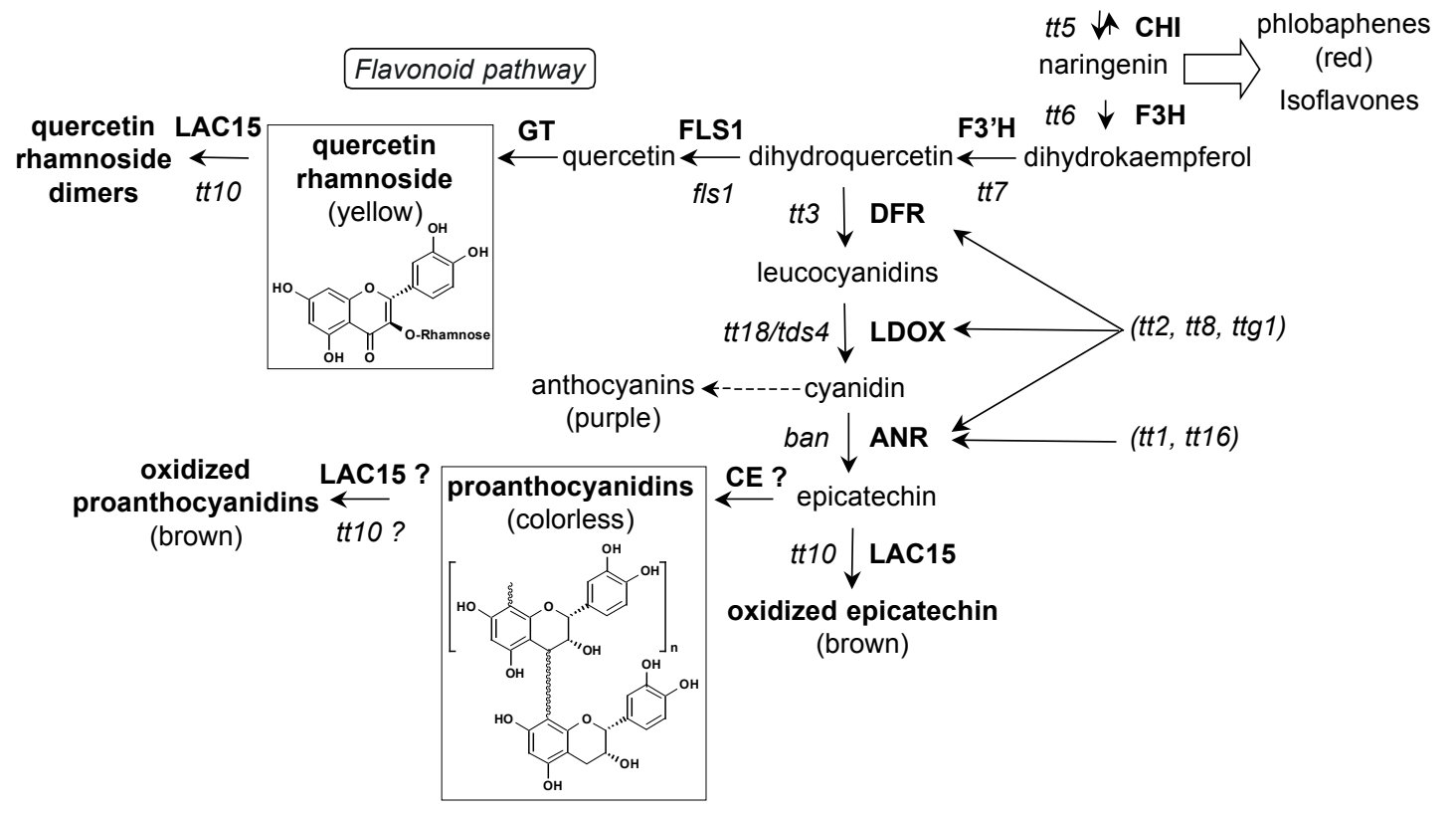


Fig. 3.5
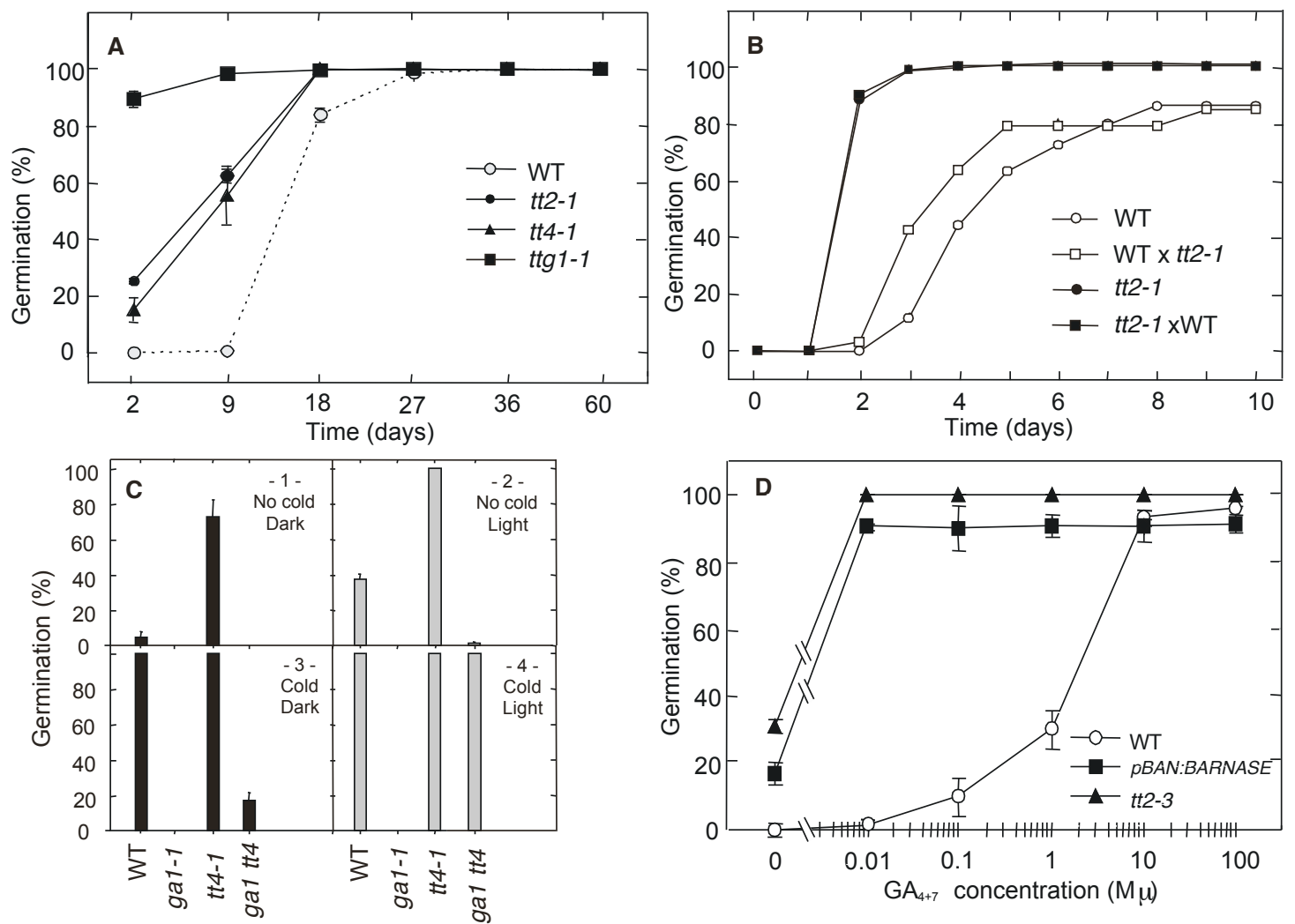